\title{
Dream and Sleep Disorders: Psychological and Pathophysiological Aspects
}

\author{
Mohammad Baloochi Anaraki ${ }^{*}$, Sadegh Rahimi ${ }^{2}$ \\ ${ }^{1}$ Faculty of Psychology and Educational Sciences, Allame Tabatabai University, Tehran, Iran \\ ${ }^{2}$ Department of Psychiatry, Ibn-e-Sina Hospital, Mashhad University of Medical Sciences, Mashhad, Iran
}

\section{A BSTRACT}

Introduction: Not only in early human societies, even today, there are people who tried to interpret dream spiritually. According to different functions of sleep and dreaming in human daily life, dream and sleep are of interest in modern science. Evolution of scientific study of dreaming during the history of medicine as well as current theories of dream have discussed in this manuscript. On the other hand, due to connection of sleep and dreaming, sleep physiology and pathology have shortly described. Conclusion: Despite of significant improvement in dream study and different theories to explain dream and sleep functions, further studies are needed to integrate all aspect of dream and sleep in human.

* Corresponding Author: Mohammad Baloochi Anaraki

E-mail: mohammad_baloochi68@yahoo.com 


\title{
اختلالات خواب و رؤيا: جنبه هاى روانشناسى و ياتوفيزيولوزى
}

\author{
محمد بلوجى اناركى '"، صادق رحيمى'
}

'دانشكده روانشناسى و علوم تربيتى، دانشعاه علامه طباطبايى، تهران، ايران

rكروه روانيزشكى، بيمارستان ابن سينا، دانشكاه علوم يزشكى مشهد، مشهد، ايران

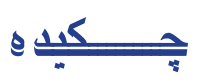

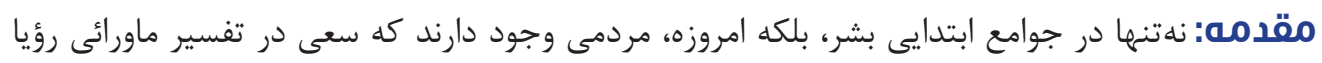

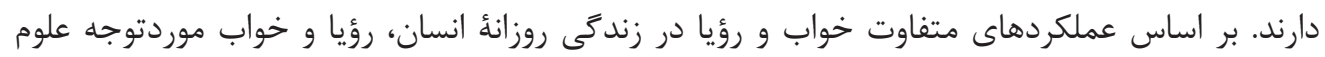

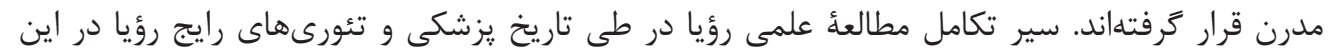

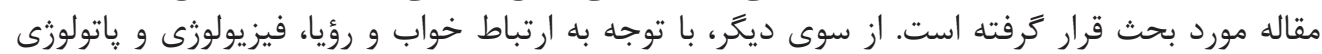

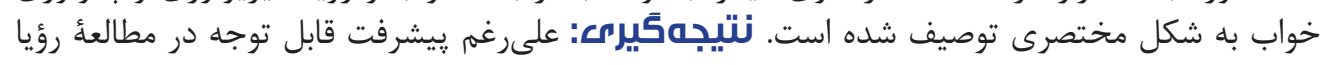

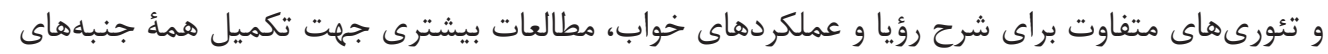
رؤيا و خواب در انسان مورد نياز است.

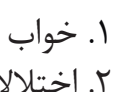

كليد وازهها:

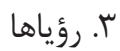

F

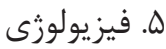

" نويسنده مسئول: محمد بلوجى اناركى " آدرس الكترونيكى: mohammad_baloochi68@yahoo.com 
نظريههاى مربوط به تجكونكى و عملكرد رؤيا و خواب از آغاز

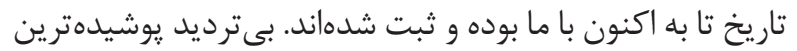

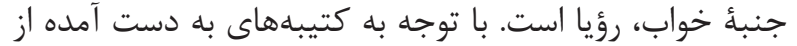

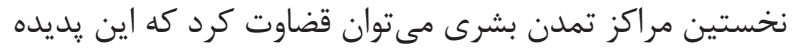

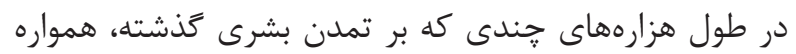

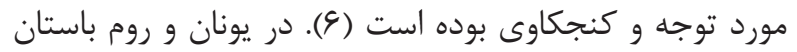

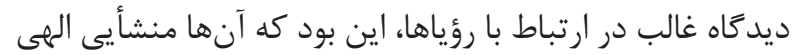

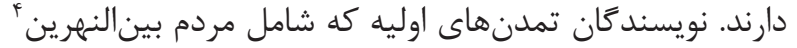

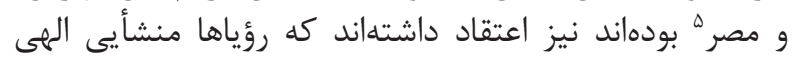

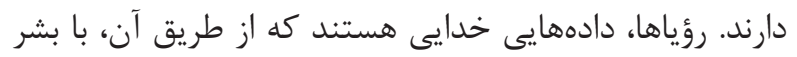
فنايذير ارتباط برقرار مى كنند (N ، N (V). اعتقاد به المهى بودن رؤيا نهتنها در نوشتههاى باستانى جندين

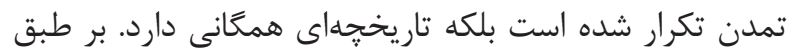

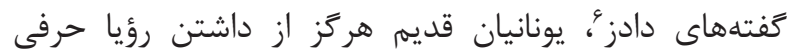

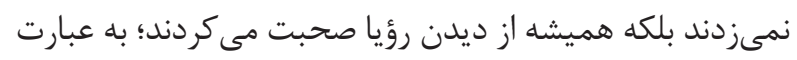

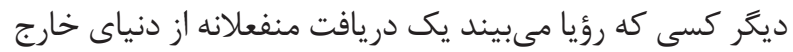

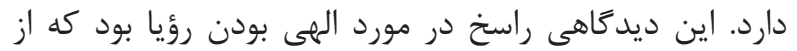

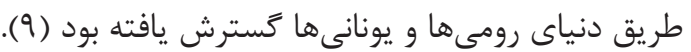

جنانجه طبيعى به نظر مىرسد كه فيلسوفان اوليه، برخى افكار

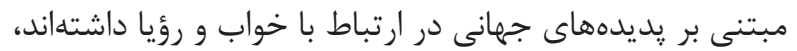

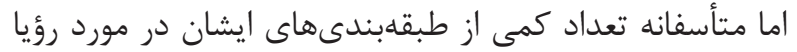

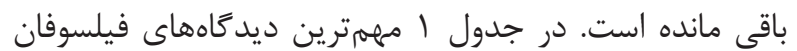
يونان باستان در مورد رؤيا آورده شده است است.

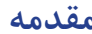

مقولهُ رؤيا، با توجه به تصويرسازى منحصر به فردى كه در آن آن

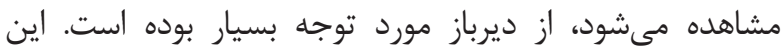

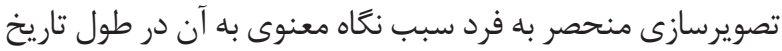

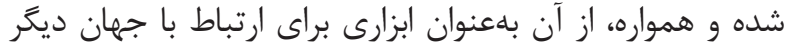

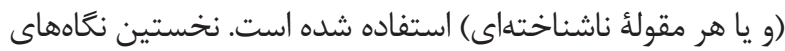

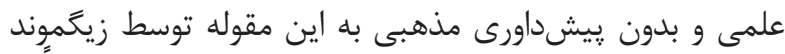

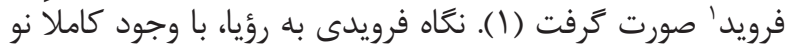

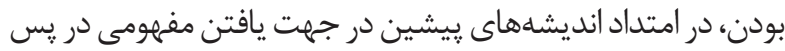

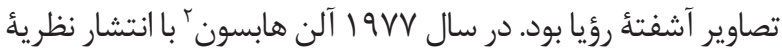

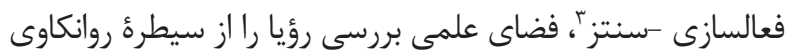

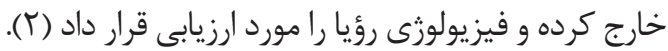
از آن زمان تاكنون :ثروهش هاى بسيارى جهت شناخت بيشتر رؤيا،

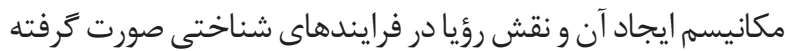

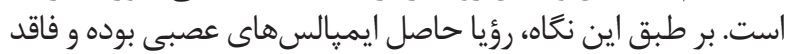

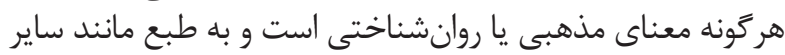

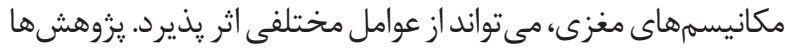

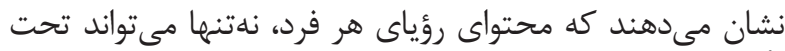

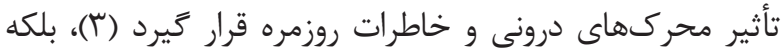

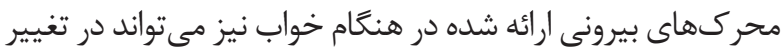

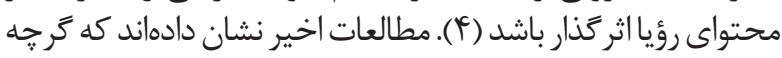

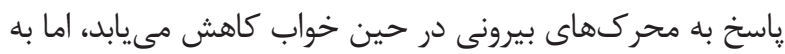

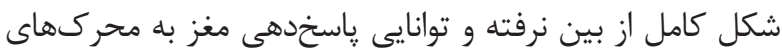

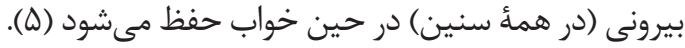

جدول ا- ديدكاه فلاسفة باستان در مورد رؤيا.

\begin{tabular}{|c|c|c|}
\hline ديد5اه & فيلسوف & رديف \\
\hline 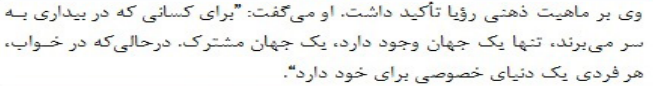 & 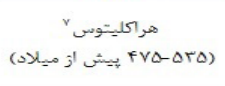 & 1 \\
\hline 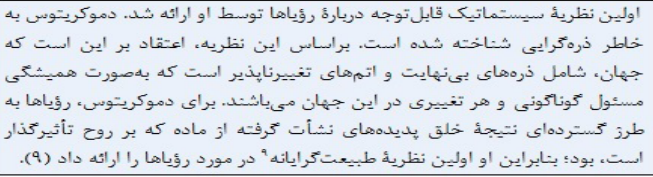 & 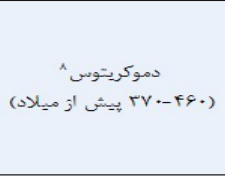 & r \\
\hline 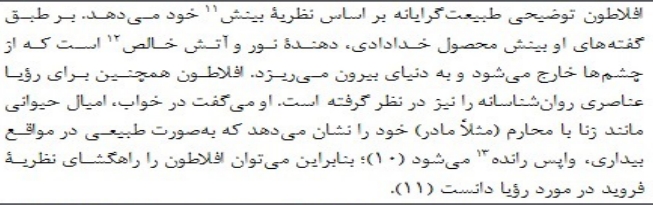 & (الفلاطون" & $r$ \\
\hline 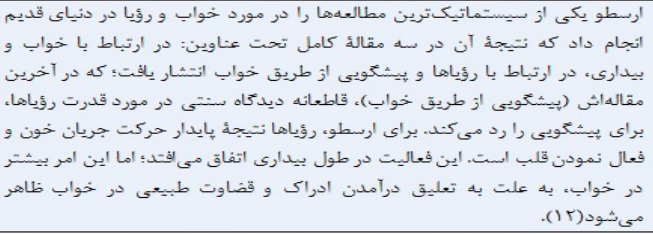 & 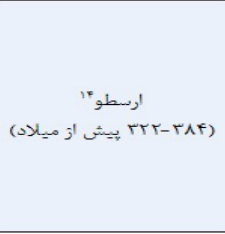 & $F$ \\
\hline 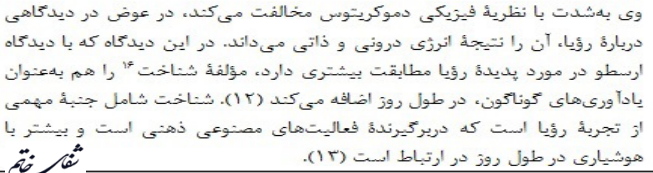 & 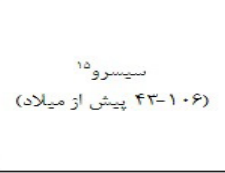 & $\Delta$ \\
\hline
\end{tabular}

${ }^{1}$ Sigmund Freud

${ }^{2}$ Allan Hobson

${ }^{3}$ Activation-synthesis hypothesis

${ }^{4}$ Mesopotamians

${ }^{5}$ Egyptia

${ }^{6}$ Dodds

${ }^{7}$ Heraclitus

${ }^{8}$ Democritus
${ }^{9}$ Naturalistic

${ }^{10}$ Plato

${ }^{11}$ Vision

${ }^{12}$ Pure fire

${ }^{13}$ Repressed

${ }^{14}$ Aristotle

${ }^{15}$ Cicero

${ }^{16}$ Cognitive 
كه به سبب دردناك يا گَناهآميز بودن بيش از حدشان، شخص

نمىتواند هشيارانه به وجود آنها آنيز بودن بيثن كند (1).

ديد

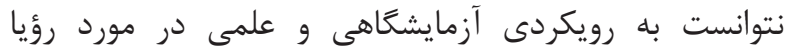

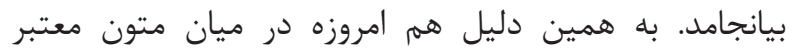

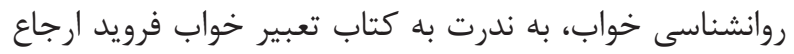

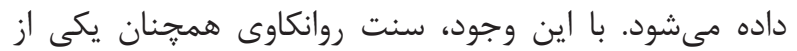

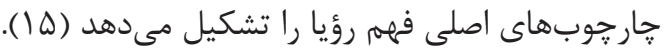

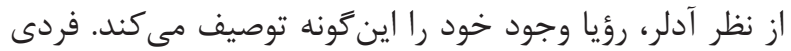

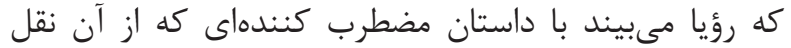

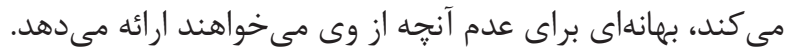

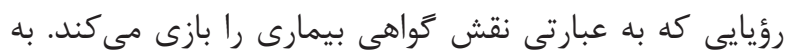

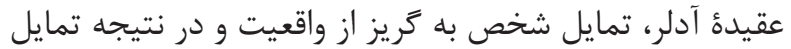

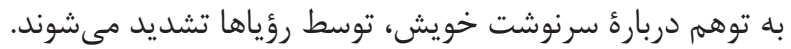

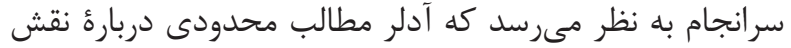

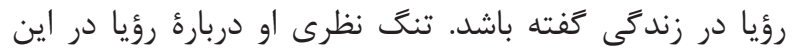

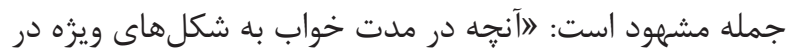

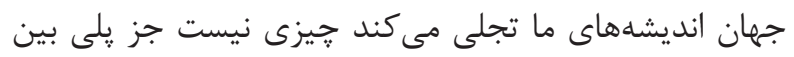
شب ييش و روز بعده (1) (1).

سنت روانكاوى فرويدى، خيلى زود به نظريهاى مشابه ولى

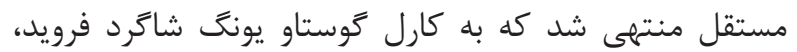

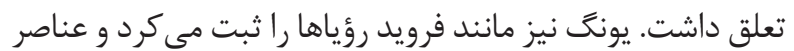

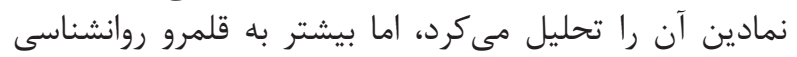

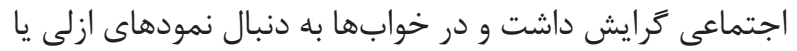

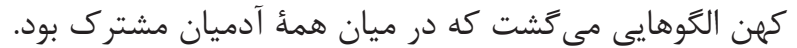

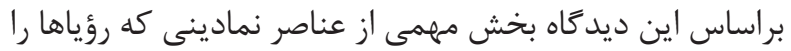

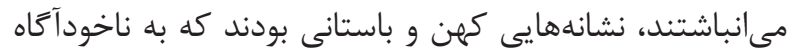

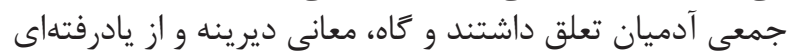
را با خود حمل مى كردند (19)

\section{يس از روانكاوى (كارهاى دامهوف، هابسون و اشنايدر)} يزوهشهاى بعدى موجب حالش بر سر جنبه دهايى از نظرئ فرويد

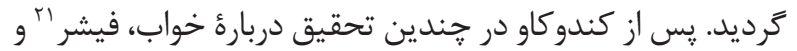

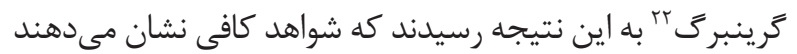

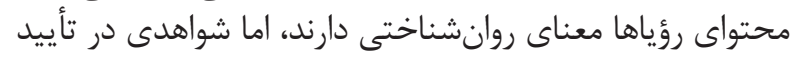

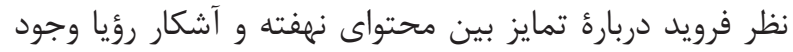

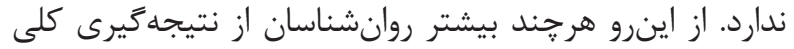

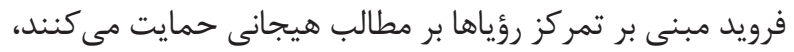

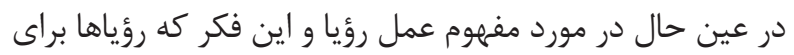
بر آورده ساختن اميال هستند، ترديد دارند (IV)

يس از فرويد، براى تبيين نقش خواب و رؤيا، نظريههاى

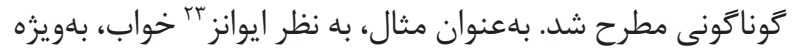

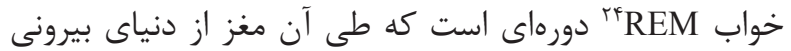

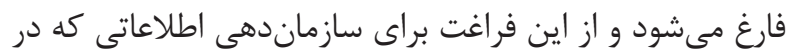

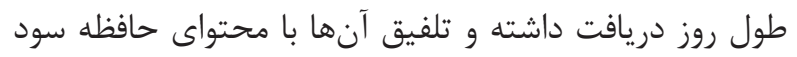

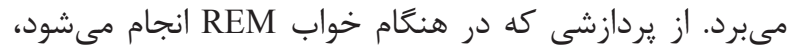

\section{${ }^{17}$ Calkins}

${ }^{18}$ Wishfulfillment

${ }^{19}$ Latent content

${ }^{20}$ Manifest
نظريه هاى مربوط به خواب همراه با رؤيا

قرون جديد (فرويد، آدلر و يونغَ)

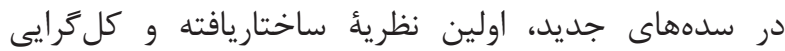

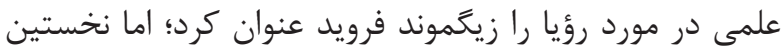

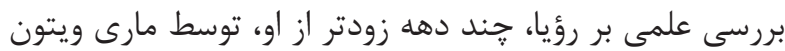

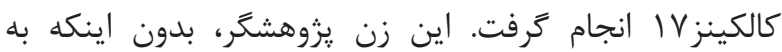
نظريهاى ساز

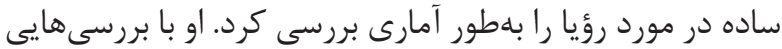

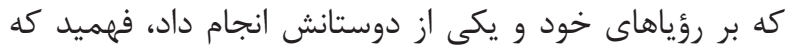

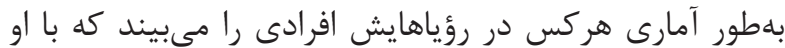

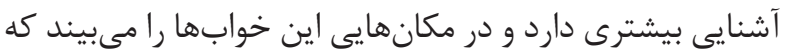

يشتر در آنجا بوده است (1) (1).

يكى از نخستين نظريهها درباره كاركرد خواب همراه با بارؤيا

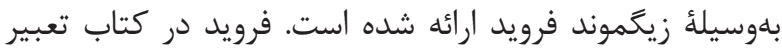

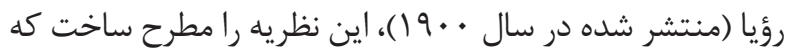

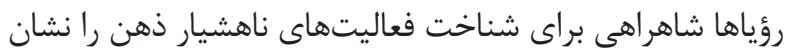

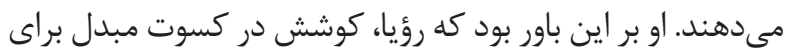

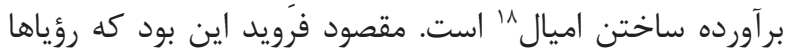

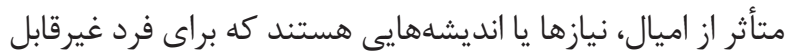

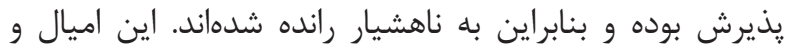

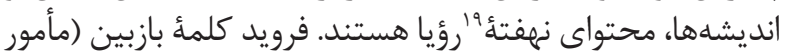

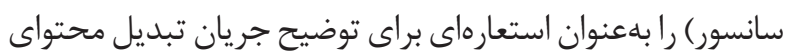

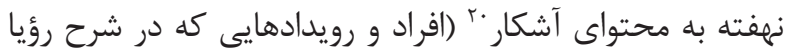

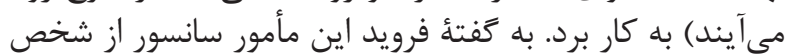

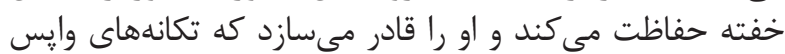

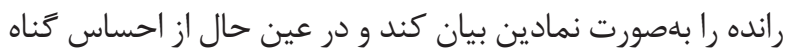

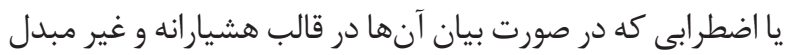

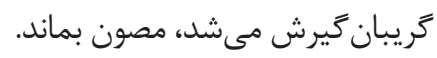

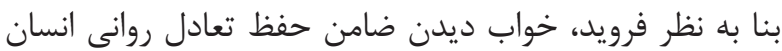

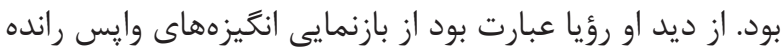

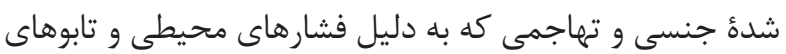

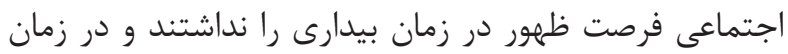

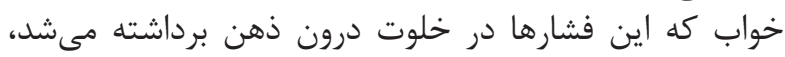

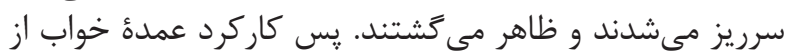

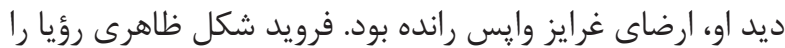

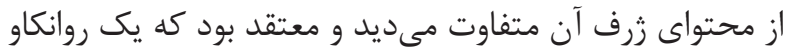

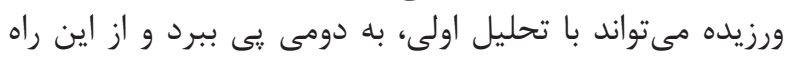

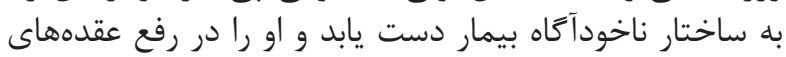

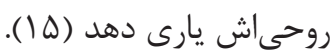

بنابر نظر فرويد، تبديل محتواى نهفتنه رؤيا به محتواى آشكار،

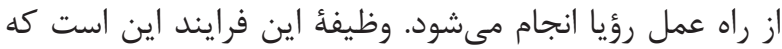

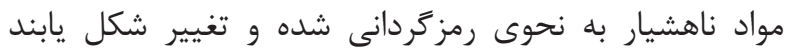

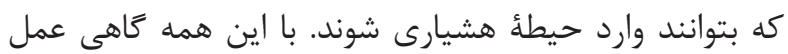

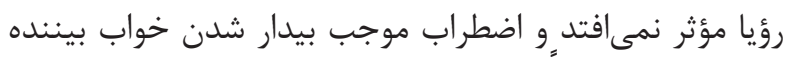

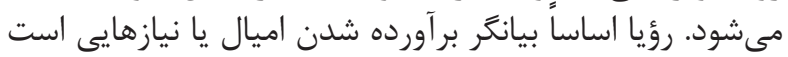

\footnotetext{
${ }^{21}$ Fisher

${ }^{22}$ Greenberg

${ }^{23}$ Evans

${ }^{24}$ Rapid eye movement
} 


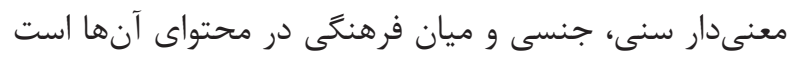
(Tr)

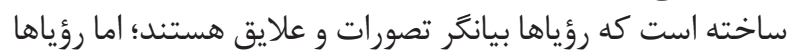

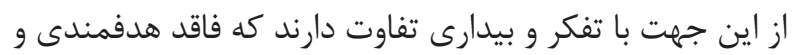

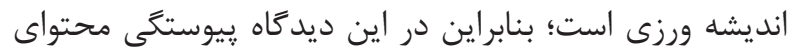
رؤيا با افكار و رفتار بيدارى، فعاليتى شناختى است (YV)

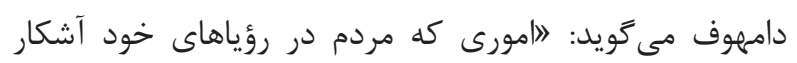

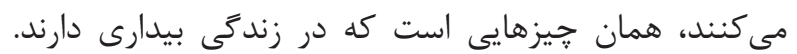

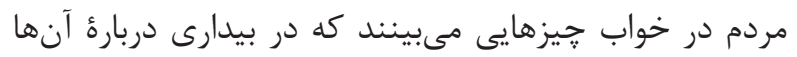

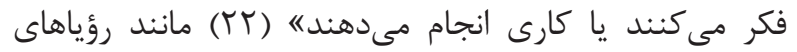

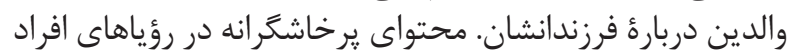

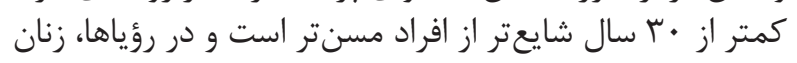

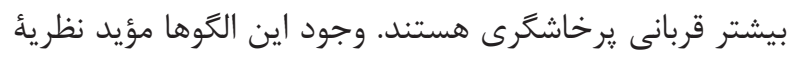

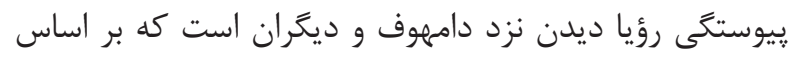

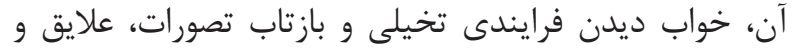
مشغلههاى ذهنى -هيجانى به شمار مىرودي

\section{نظريههاى فيزيولوزيك در مورد خواب و رؤيا}

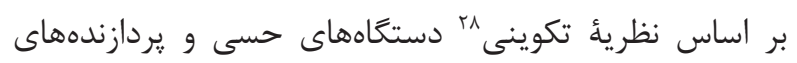

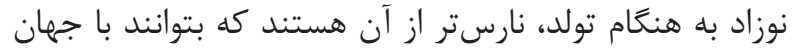

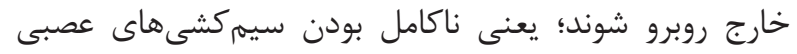

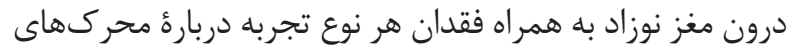

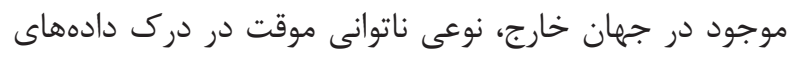

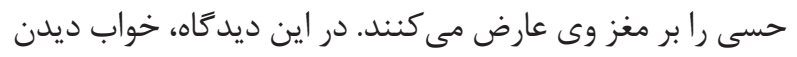

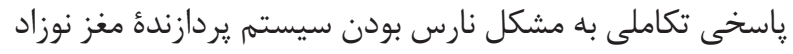

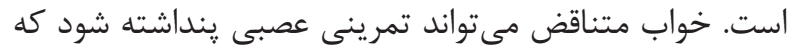

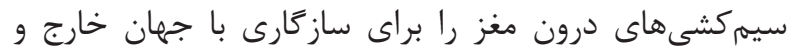

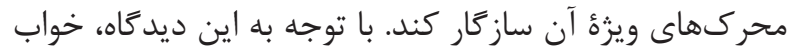

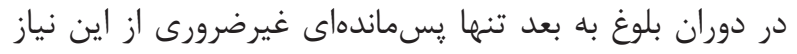

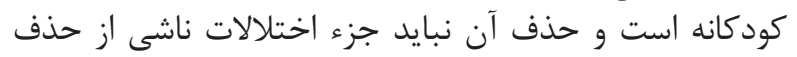

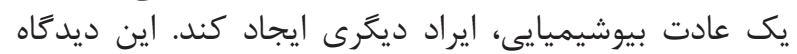

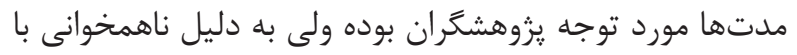

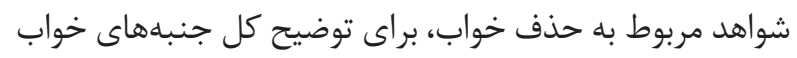

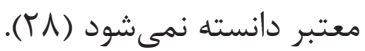

بر اساس نظرئ كريخ -ميتجِيسن، ما مى خوابيم تا خاطرات

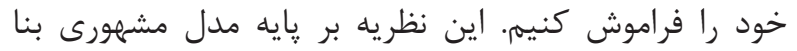

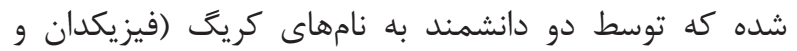

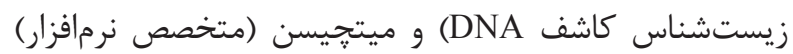

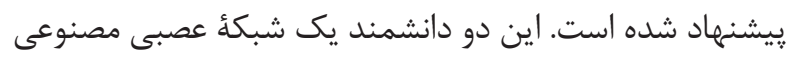

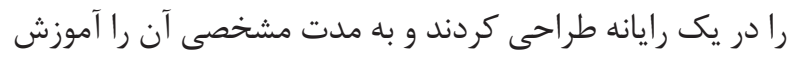

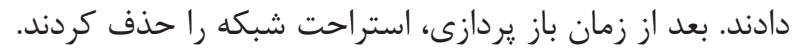

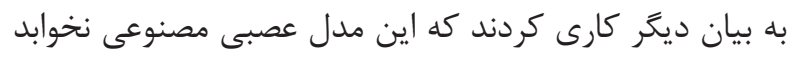

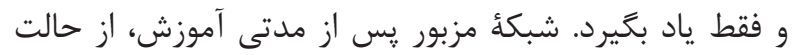

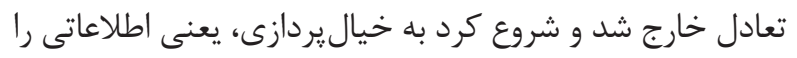

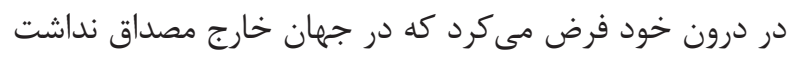

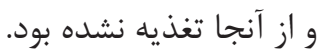

${ }^{25}$ Hobson

${ }^{26}$ Delirium

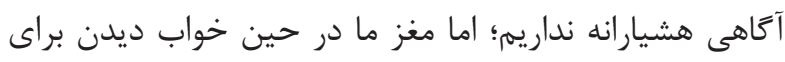

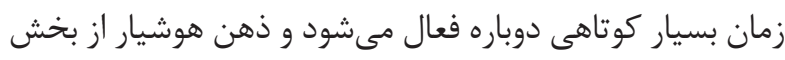

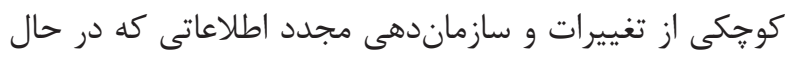

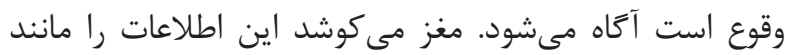

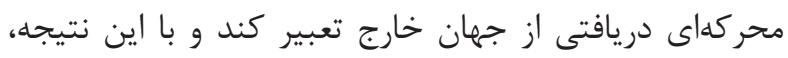

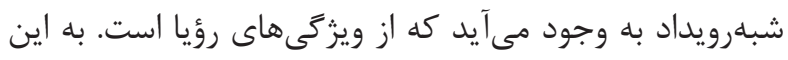

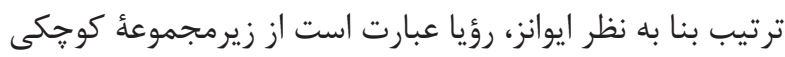

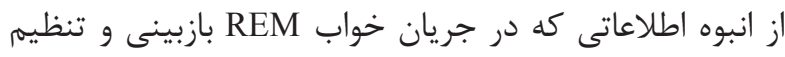

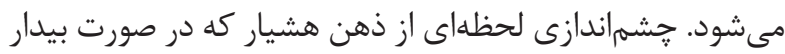

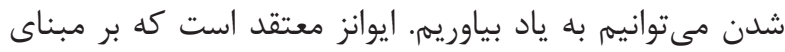

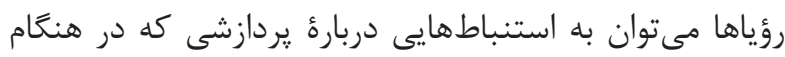

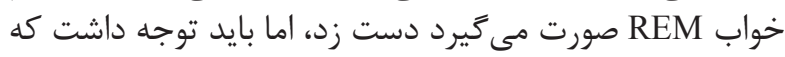

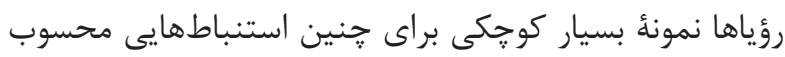

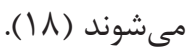

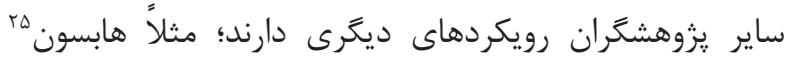

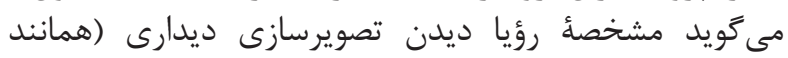

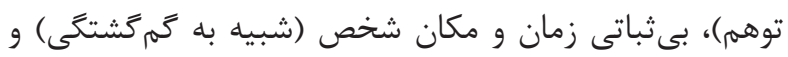

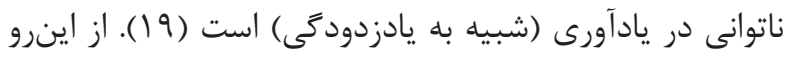

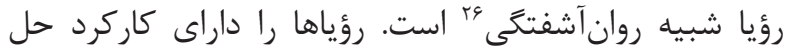

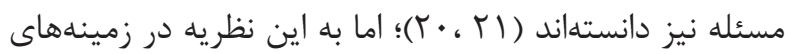

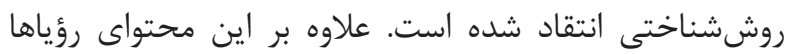

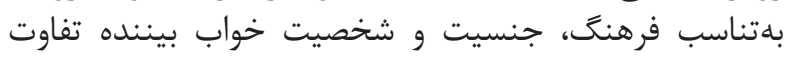

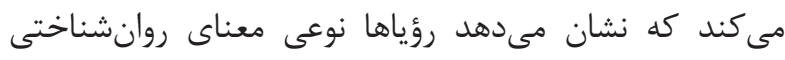

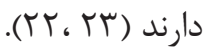

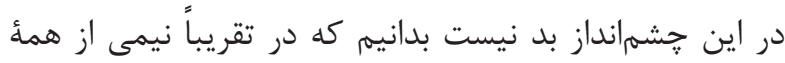

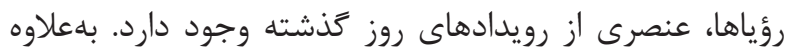

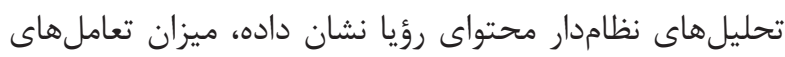

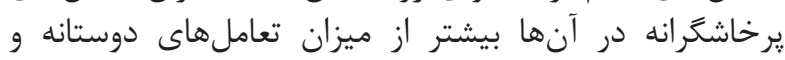

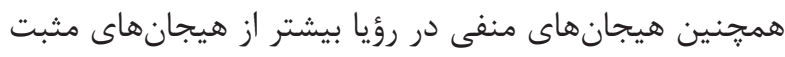

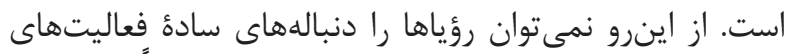

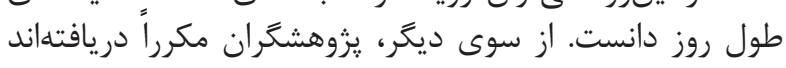

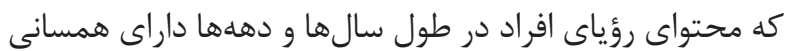

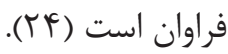

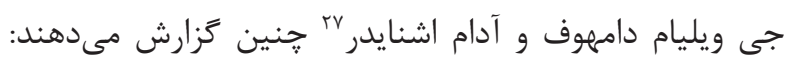

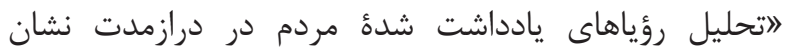

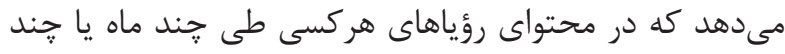

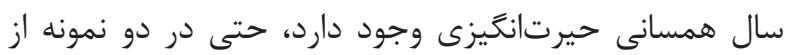

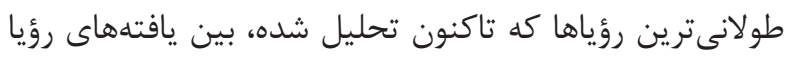

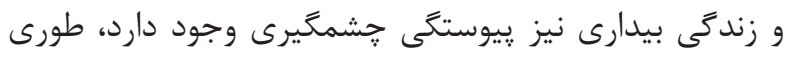

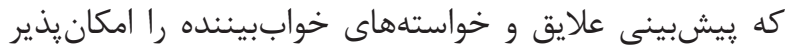

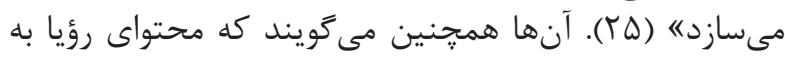

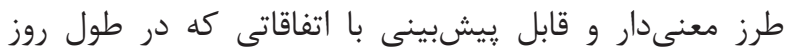

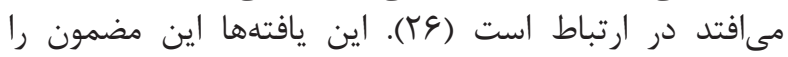
مىرساند كه رؤياها داراى معنا هستند. علاوه بر اين تحليل رؤياها حاكى از شباهتها و تفاوتهاى هوناي

${ }^{27} \mathrm{G}$ William Domhoff and Adam Schneide

${ }^{28}$ Developmental hypothesis 


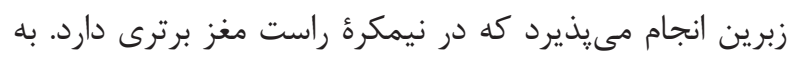

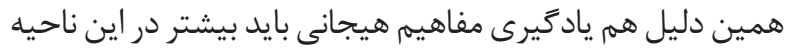

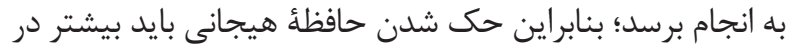

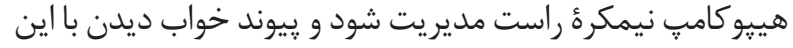

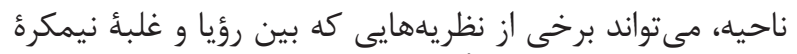

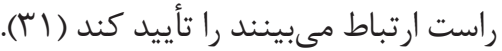

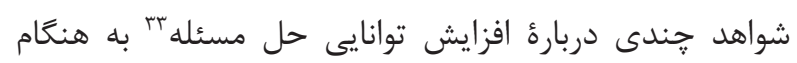

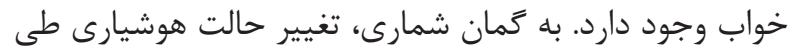

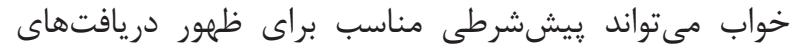

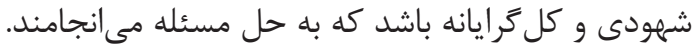

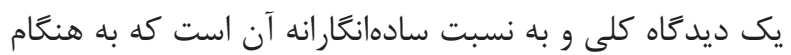

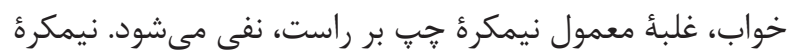

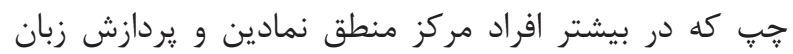

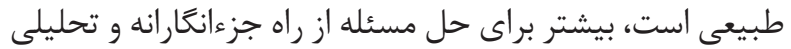

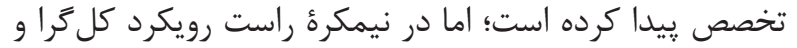

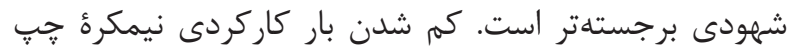

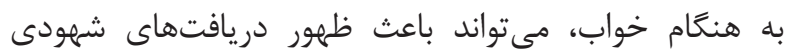

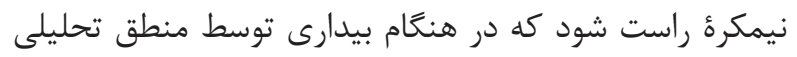

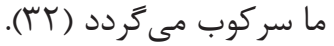

شواهد زندگىنامهاى فراوانى وجود دارد كه امكان بروز جنين

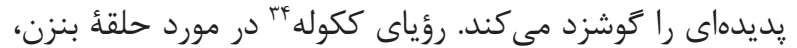

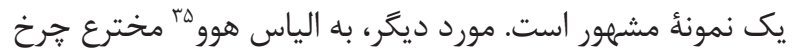

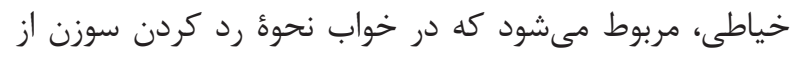

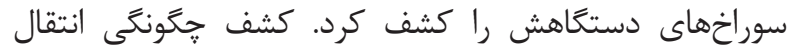

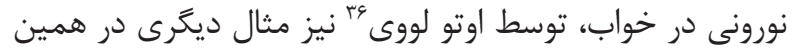

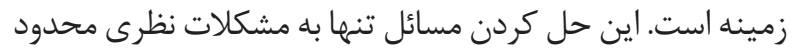

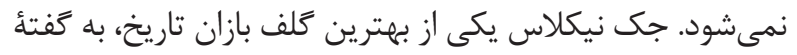

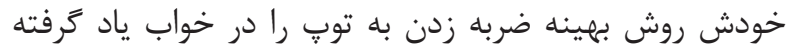

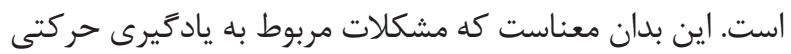
هم مىتوانند در خواب گشوده شوند (Tr). ويرُكى هاى عمومى خواب خواب در معناى كلى، رفتارى عام و رايج در ميان همأ جانوران

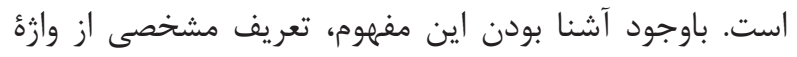

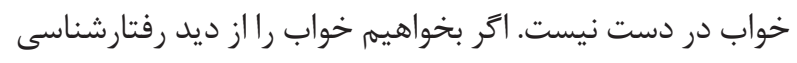

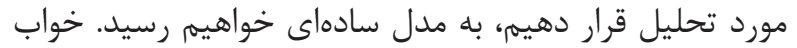

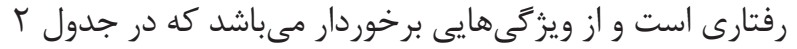

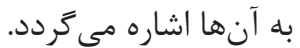

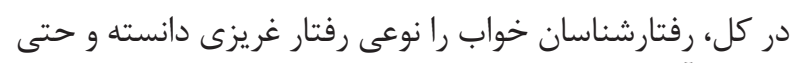

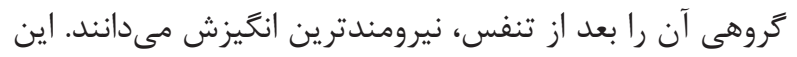

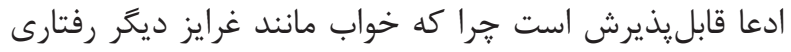

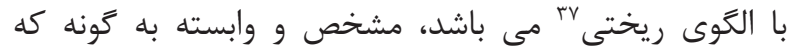

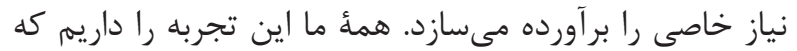

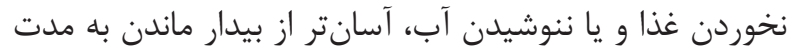

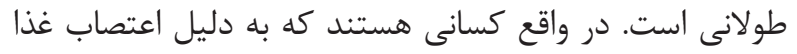

\footnotetext{
${ }^{29}$ Activation-synthesis

${ }^{30}$ Limbic system

${ }^{31}$ Memory consolidation

${ }^{32}$ Consolidation

${ }^{33}$ Problem solving
}

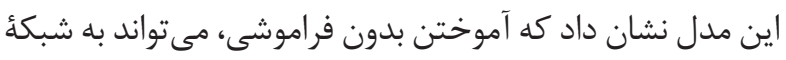

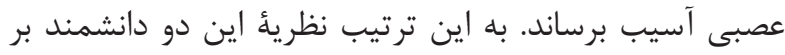

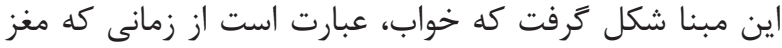

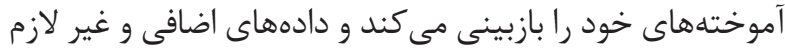

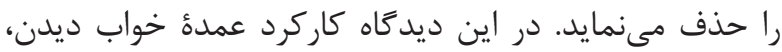

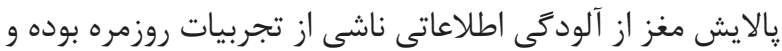

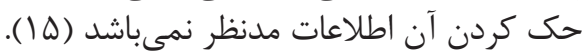

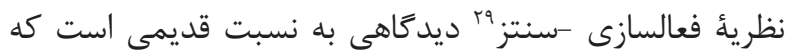

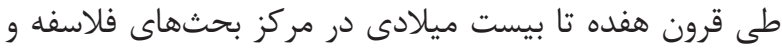

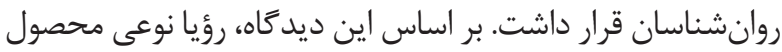

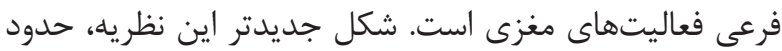

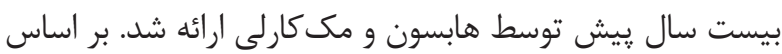

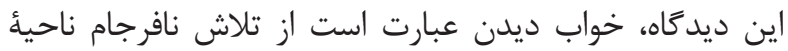

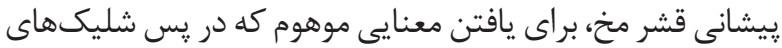

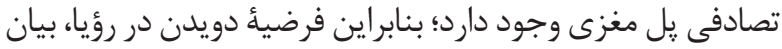

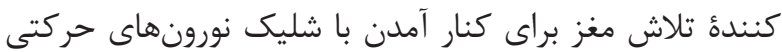

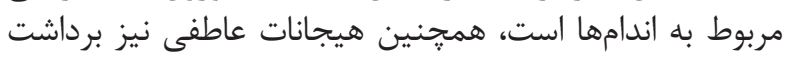

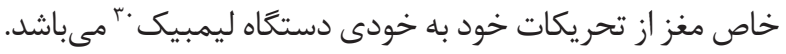

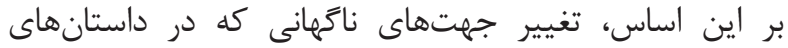

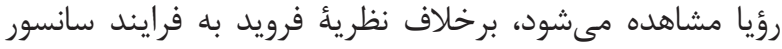

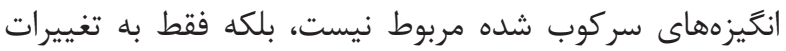

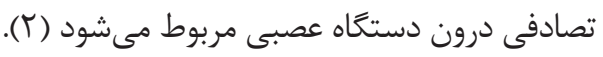

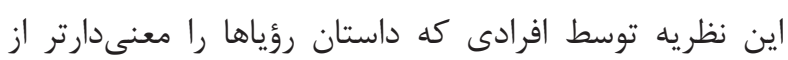

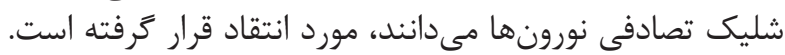

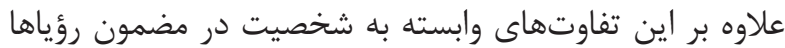

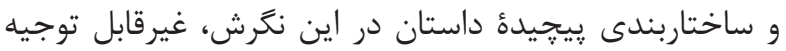

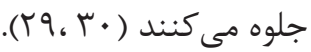

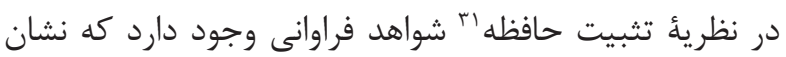

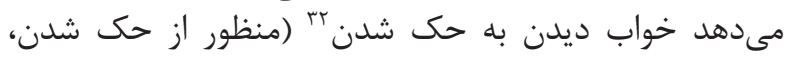

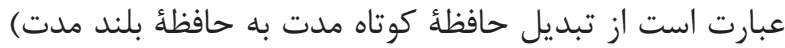

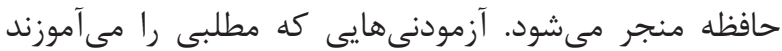

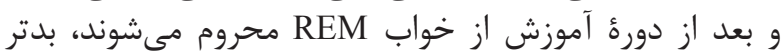

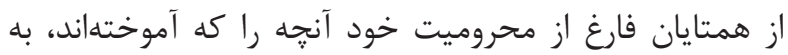

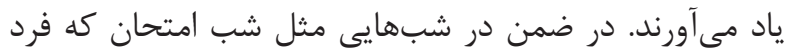

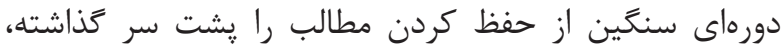

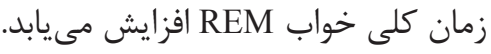

شواهد تجربى نشان مىدهند كه بهويزه اطلاعات داراى بار

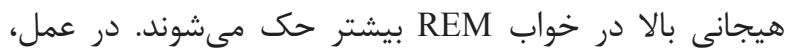

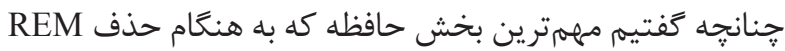

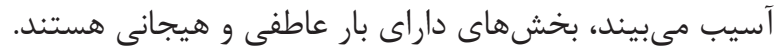

اين رابطةٔ ميان خواب ديدن و ثبت ثبت دادههاى هيجانى،

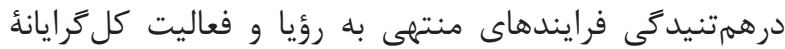
نيمكرة راست مغز ناشى مئى فرود.

يردازش دادهاى هيجانى و عاطفى بيشتر در ساختار كل كرايانئ
${ }^{34}$ Kekule

${ }^{35}$ Elias Howe

${ }^{36}$ Otto Loewi

${ }^{37}$ Stereotypic 


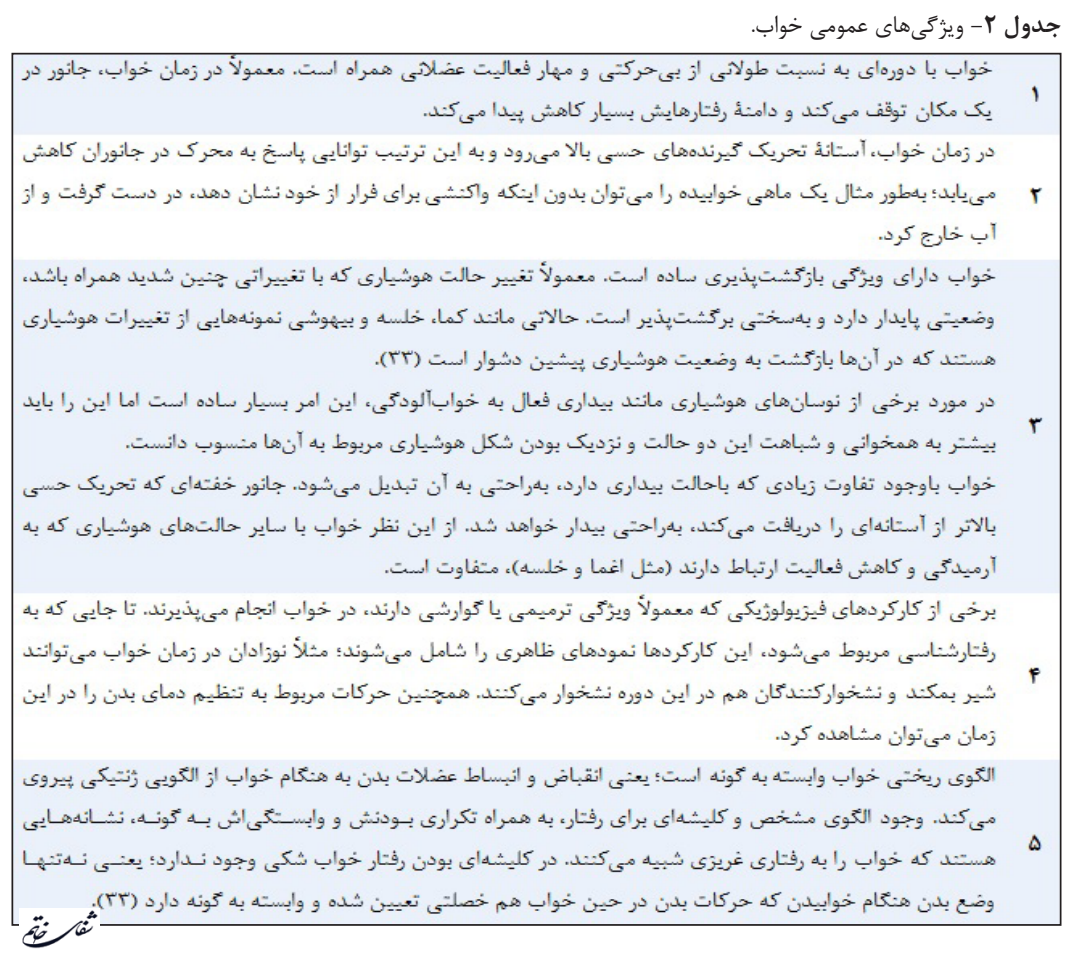

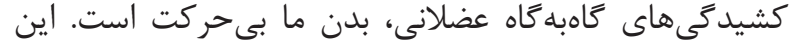

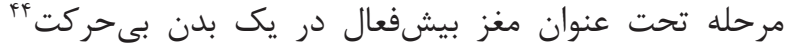

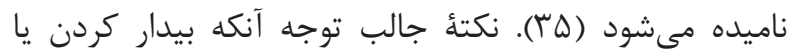

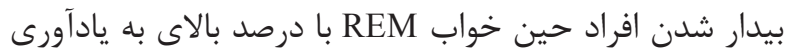

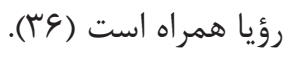

از بين رفتن تونوس عضلانى يك رفتار ييوستهاى است كه در

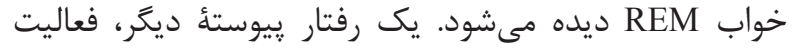

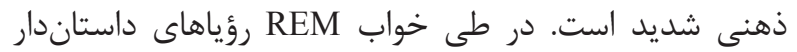

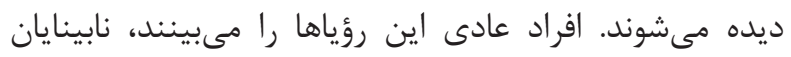

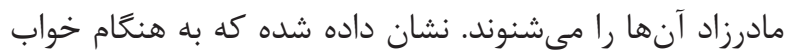

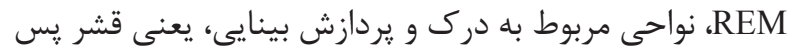

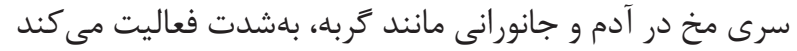

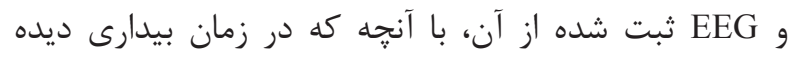

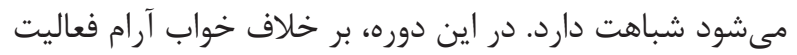

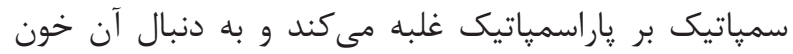

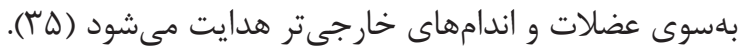

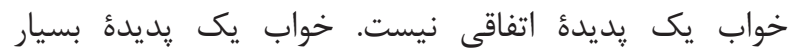

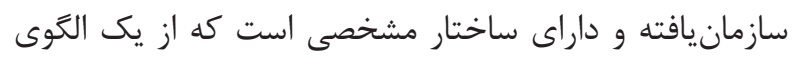

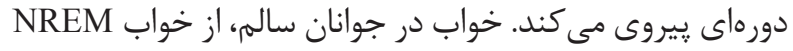

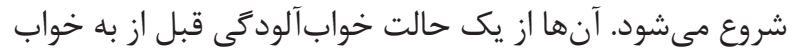

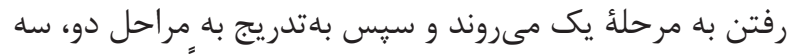

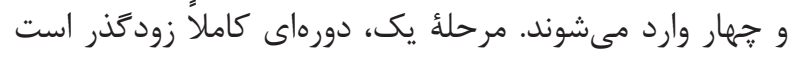

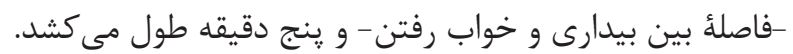

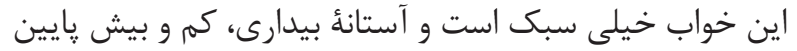

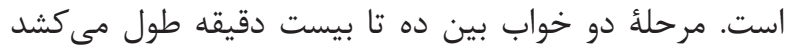

\footnotetext{
${ }^{38}$ Non- rapid- eye- movement

${ }^{39}$ Quiet

${ }^{40}$ Idling brain in movable body

${ }^{41}$ Paradoxical
}

و خوددارى از خوردن آب و غذا مرده باشند، اما كسى را سراغ

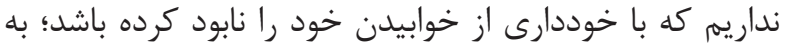

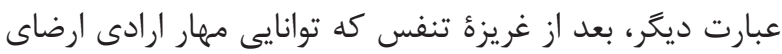

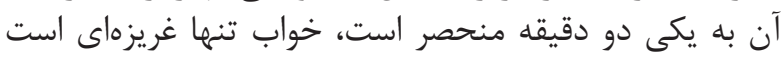

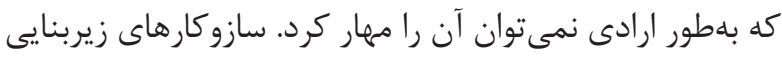

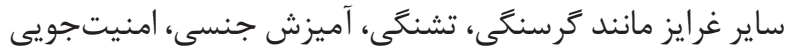

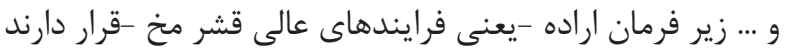

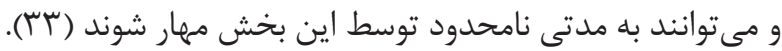

$$
\text { ماهيت و مراحل خواب }
$$

محققين دو نوع خواب را مشخص كردهاند: خواب REM و NREM

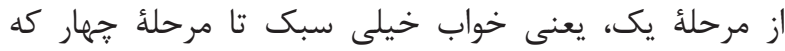

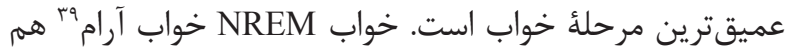

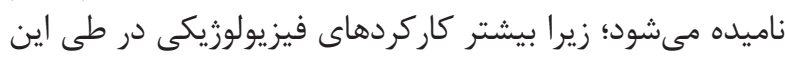

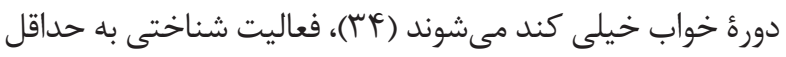

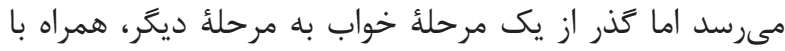

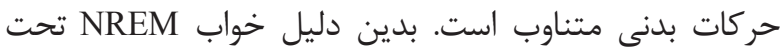

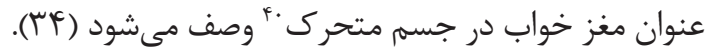

برعكس، خواب REM تحت عنوان خواب متناقض أ، فعال يا

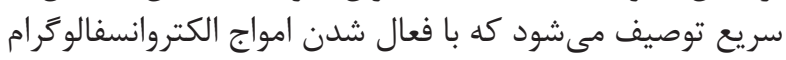
تجر (EEG)

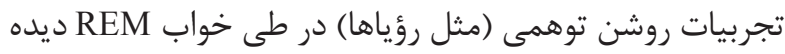

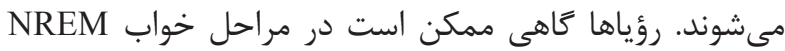

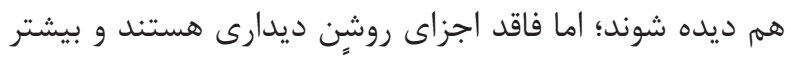

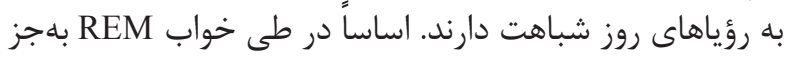

\footnotetext{
${ }^{42}$ Electroencephalogram

${ }^{43}$ Muscle atonia

${ }^{44}$ Hyperactive brain in a paralyzed body
} 
فراموشى در مورد وقايع قبل از به خواب رفتن يا يس از بـ بيدار

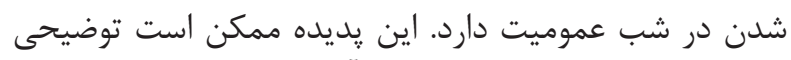

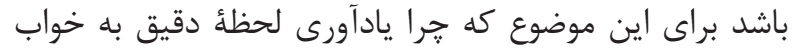

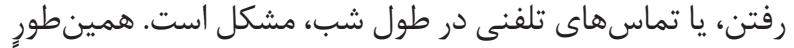

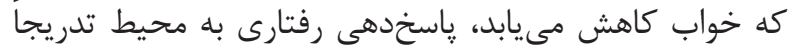

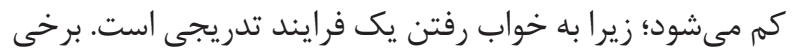

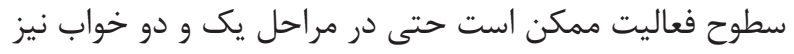

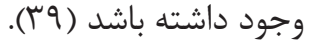

باسخدهى به محيط همجنين بلوسيلة محرك كهاى با اهميت

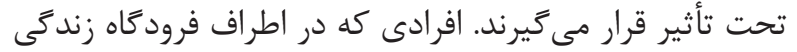

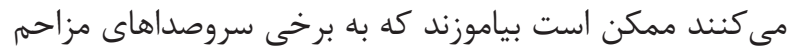

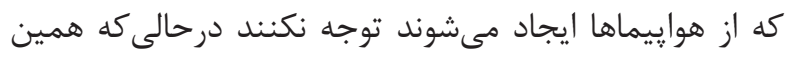

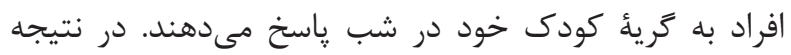

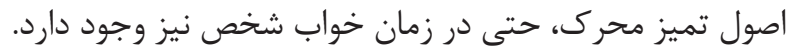

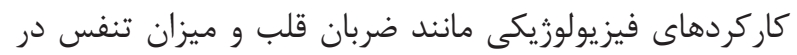

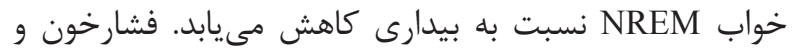

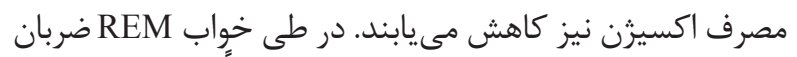
قلب و ميزان تنفس افزايش مئى ميابند (غالباً بالاتر از سطوح

معمولى) و نامنظهمر مىشوند (†) (Y).

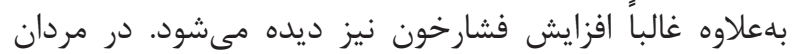

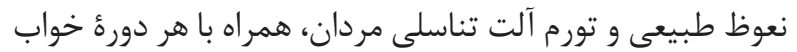

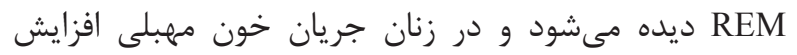

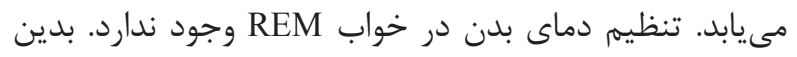

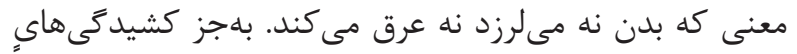

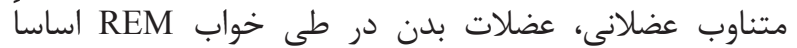

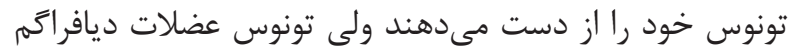

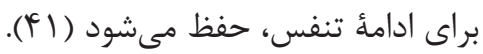

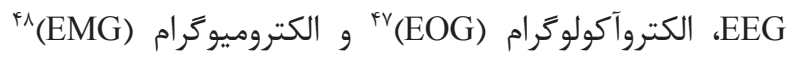

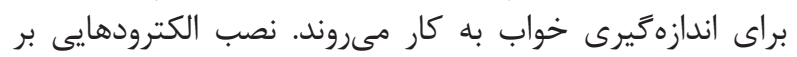

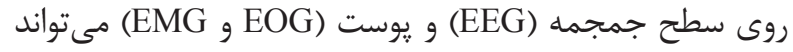

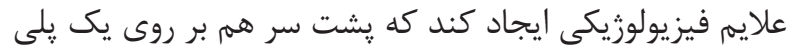

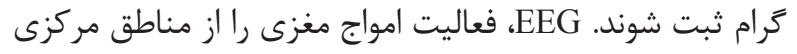

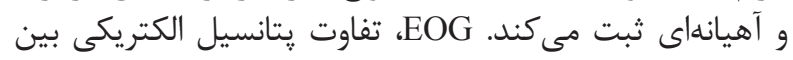

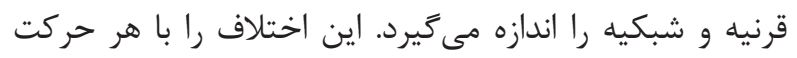

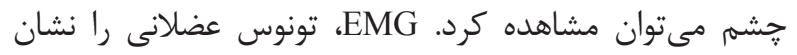

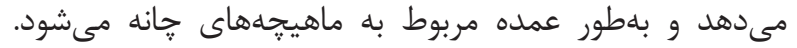

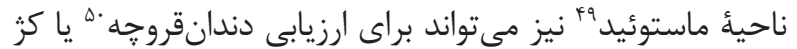

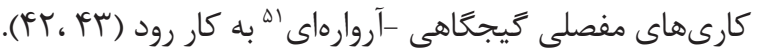

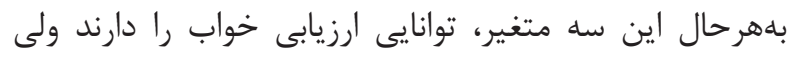

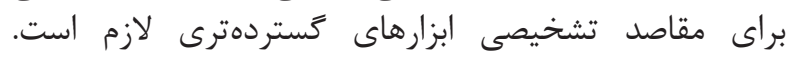

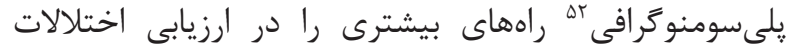

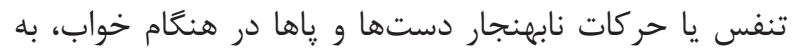

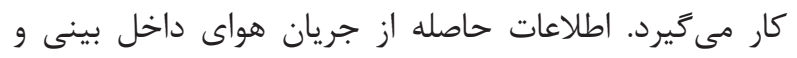

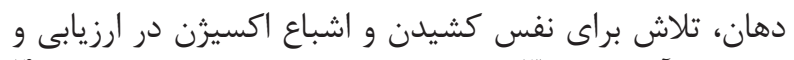

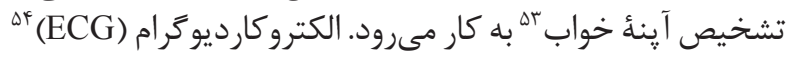

\footnotetext{
${ }^{45}$ Slow-wave

${ }^{46}$ Ponto-geniculo-occipital waves

${ }^{47}$ Electro-aculogram

${ }^{48}$ Electromyogram

${ }^{49}$ Mastoid area
}

و خواب فيز يولوزيكى واقعى ناميده مىشود زيرا با تجربئ بديدار

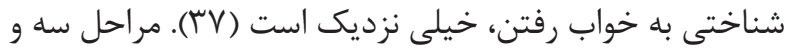

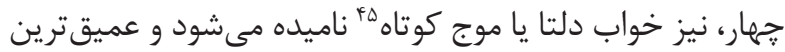

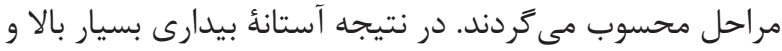

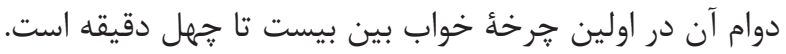

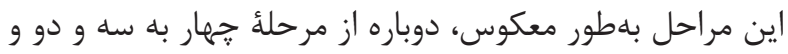

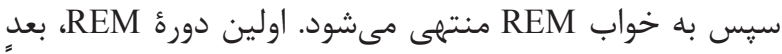

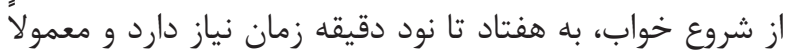
طول مدت آن كوتاه است (بين ه تا ها ها دقيقه).

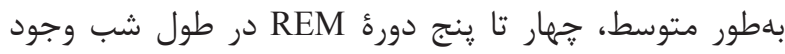

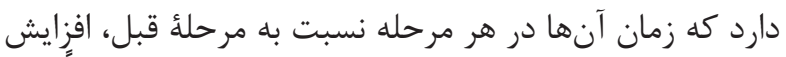

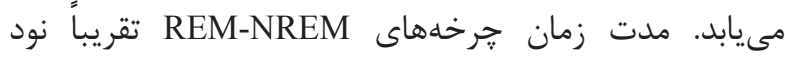

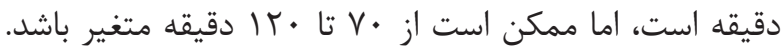

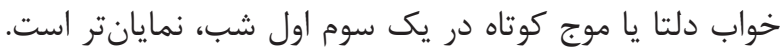

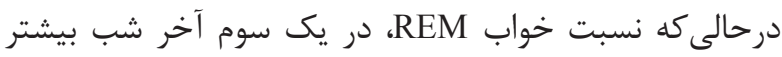

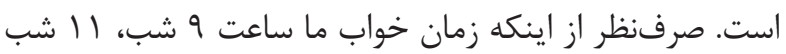

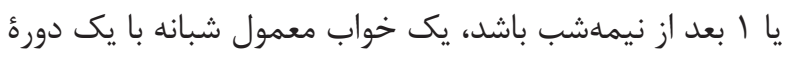

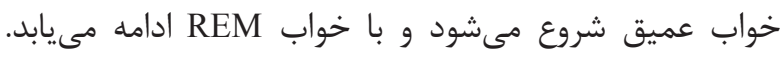

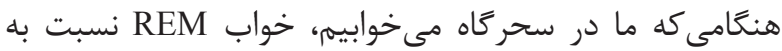

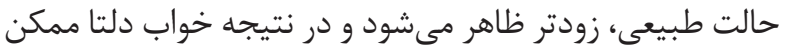
است ديرتر ظاهر گرديده و كوتاهتر باشد.

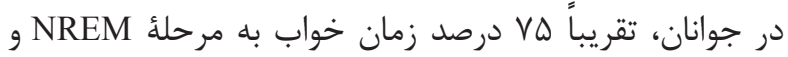

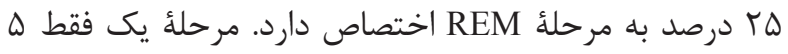

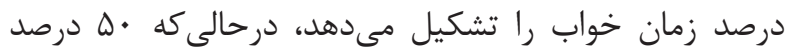

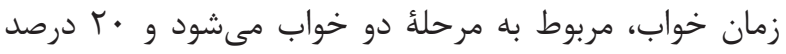

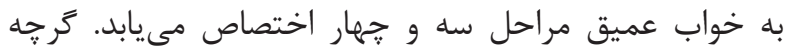

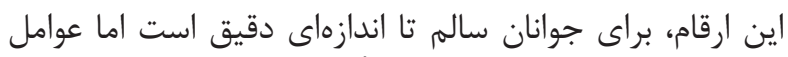

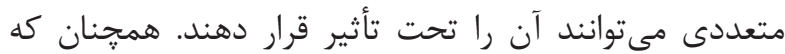

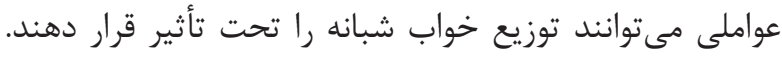

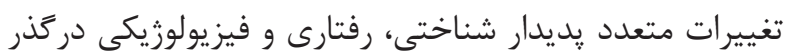

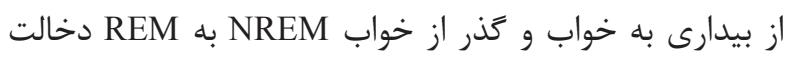

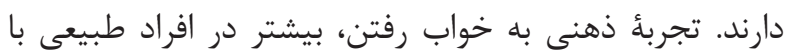

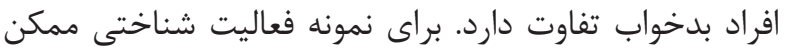

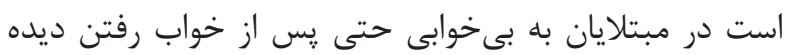

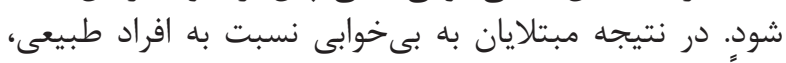

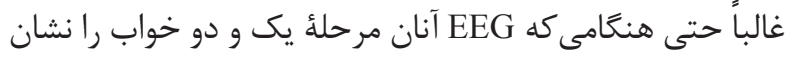

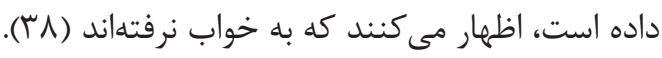

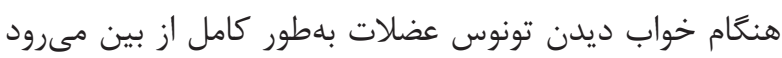

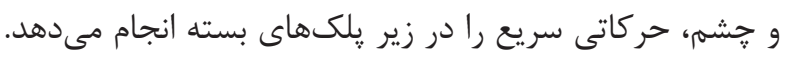

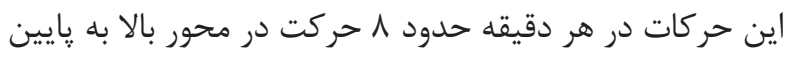

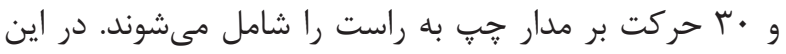

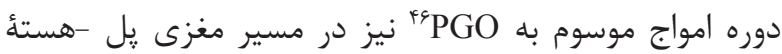

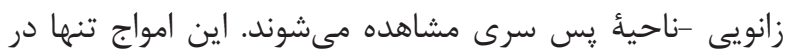

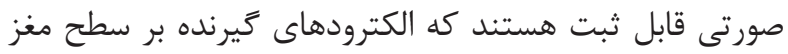

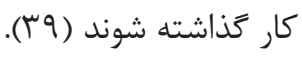

\footnotetext{
${ }^{50}$ Bruxism

${ }^{51}$ Temporomandibular

${ }^{52}$ Polysomnography

${ }^{53}$ Sleep apnea

${ }^{54}$ Electrocardiogram
} 


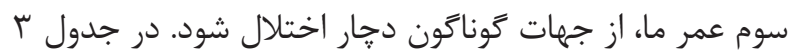

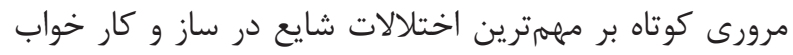

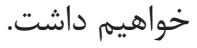

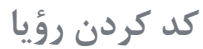
براى بيشتر از يك قرن است كه روانشناسان و ديكر دانشمندان

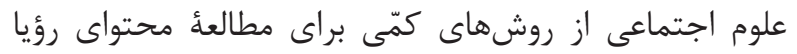

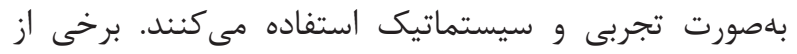

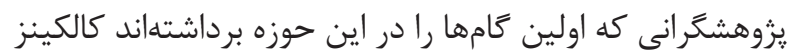

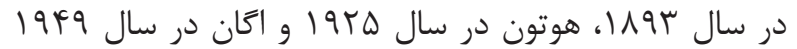

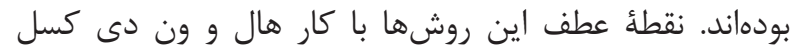

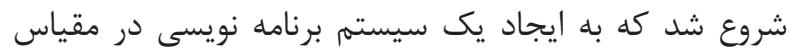

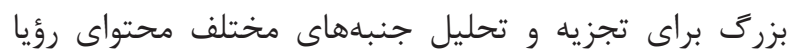

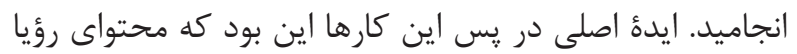

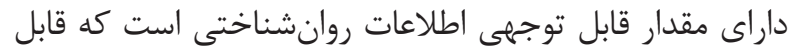

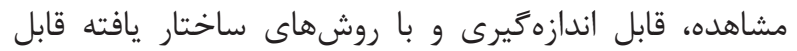

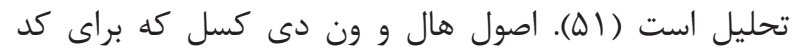

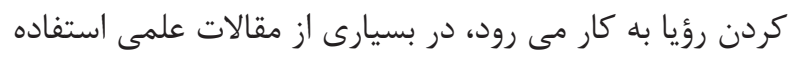

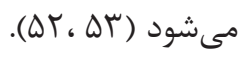

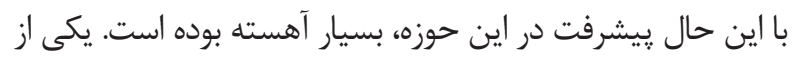

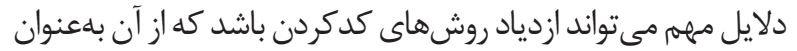

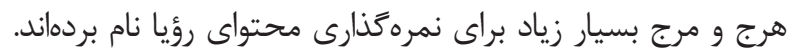

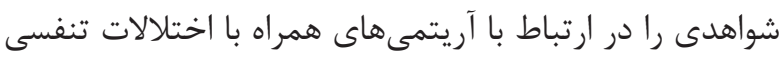

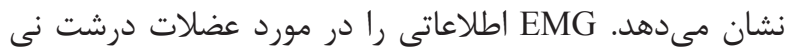

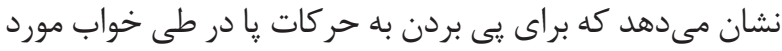

استفاده واقع مىشوند (FF).

تمامى ابزارهاى اندازهخيرى الكتروفيزيولوزيكى EEG و

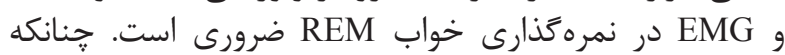

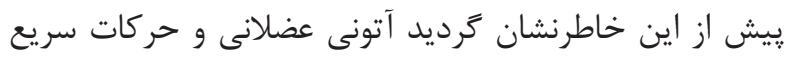

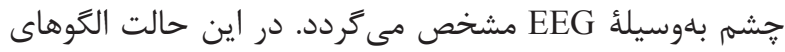

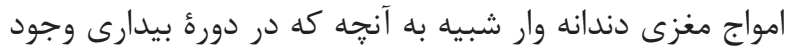

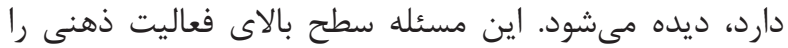

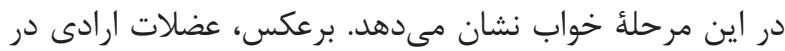

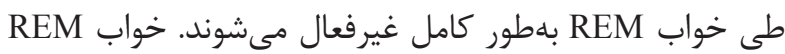

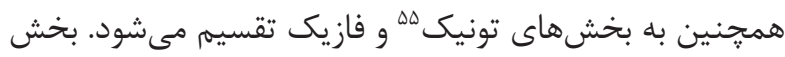

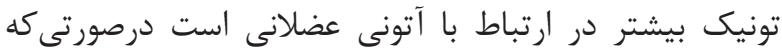

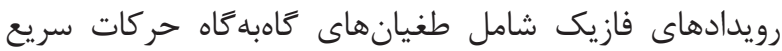

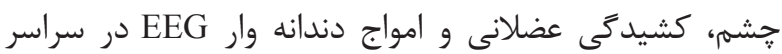

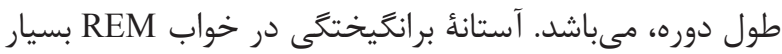

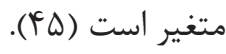

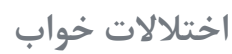
خواب كاركردى است يِيجيده كه از بسيارى از جنبه بها مي تواند

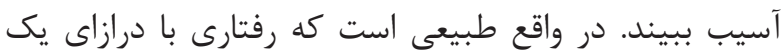

جدول ب- تعريف اختلالات خواب و شايعترين آنها.

\begin{tabular}{|c|c|c|}
\hline تعريف & نوع اختلال & رديف \\
\hline 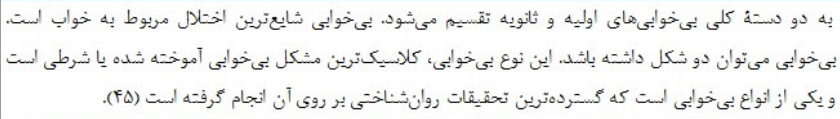 & بىخوابى & 1 \\
\hline 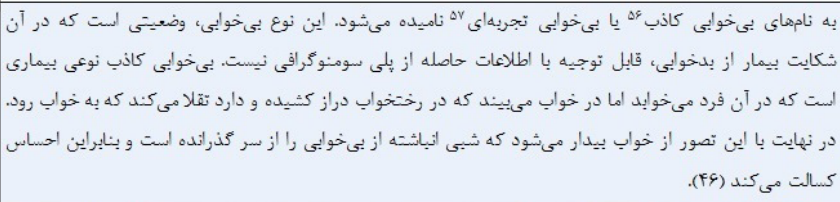 & سو خوتعبير وضعيت & $r$ \\
\hline 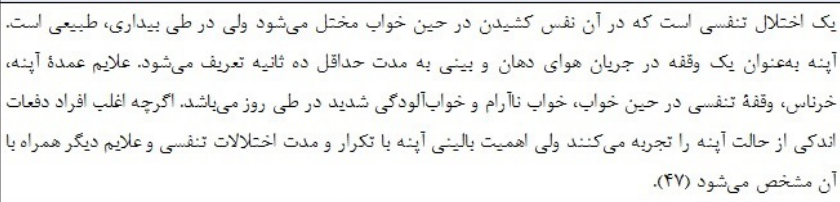 & آينة خواب & $r$ \\
\hline 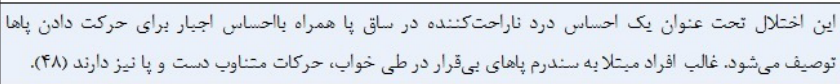 & 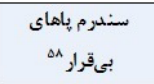 & F \\
\hline 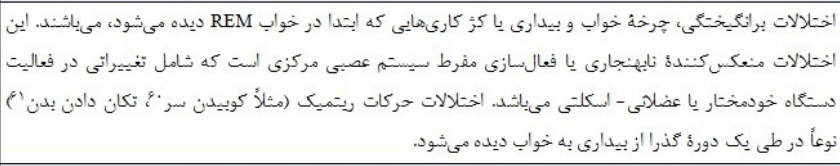 & 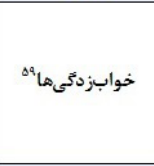 & $\Delta$ \\
\hline 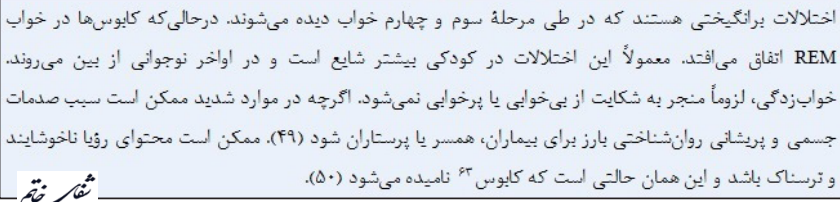 & خوابهو وحشت روتن & 9 \\
\hline
\end{tabular}

${ }^{55}$ Tonic

${ }^{56}$ Pseudoinsomnia

${ }^{57}$ Experiental insomnia

${ }^{58}$ Restless-legs syndrome

${ }^{59}$ Parasomnia
${ }^{60}$ Head banging

${ }^{61}$ Body rocking

${ }^{62}$ Somnambulism

${ }^{63}$ Nightmare 


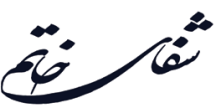

نفر كه جمعاً . .مه رؤيا مىشود) و براى هر يك از مواردى كه در زير آورده مىشود هنجار شده است.

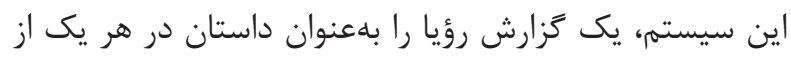

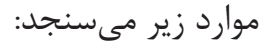
• وجود يك شخصيت (حيوان، مردان يا زنان، دوستان و غريبه نا) • يك سرى تعاملات اجتماعى (يرخاشكرى، روابط دوستانه و روابط جنسى) • • فعاليتهاى مختلف (فكر كردن، حرف زدن و دويدن يا

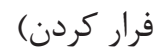

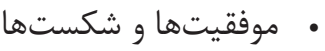

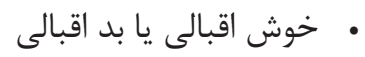

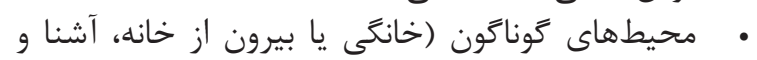
غير آشنا) • اشيا (صندلىها، ماشينها، خيابانها و اعضاى بدن)

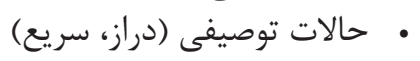

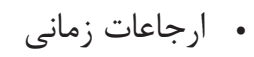

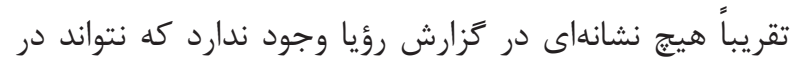

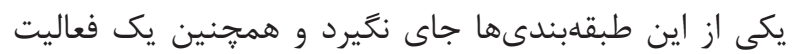

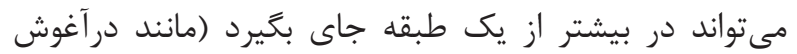

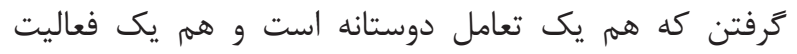

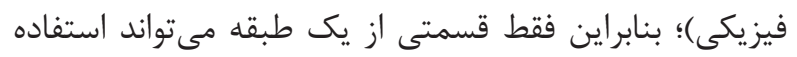

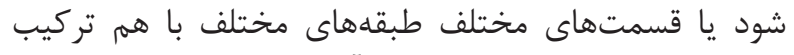
شوند و طبقهاى جديد را به وجود آورند (AF).

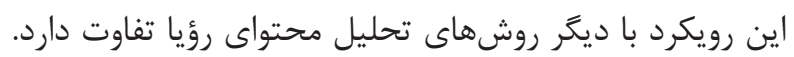

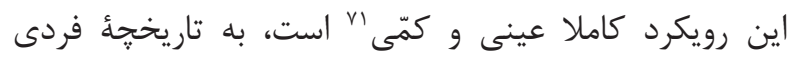

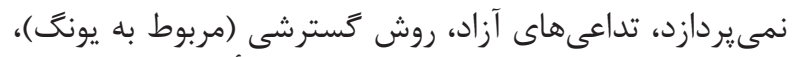

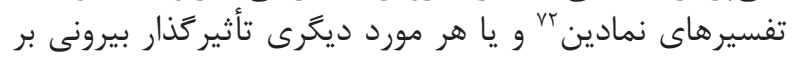

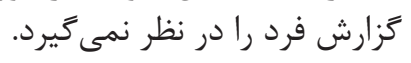

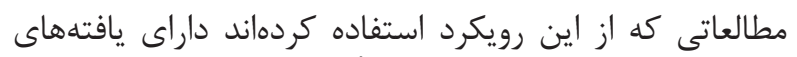

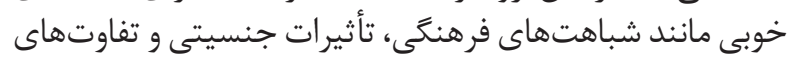

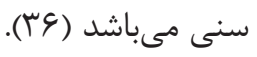

سيستم هال و ون دى كسل كه بهنوعى تحلى تحليل كمّى محتوا است شامل موارد زير مى ون دياشد:

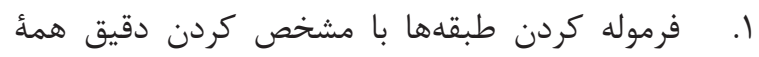

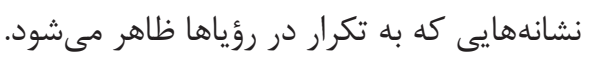

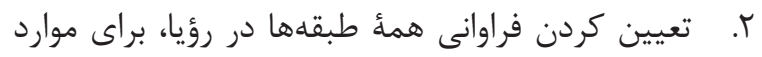
فردى و گروهى.

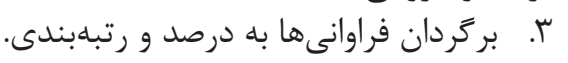

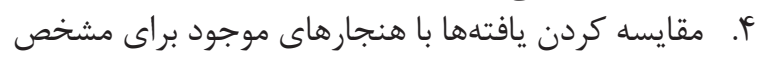

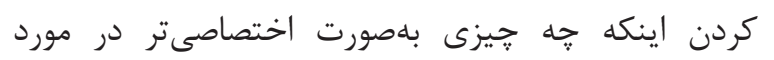
رؤياهاى شخص يا گَروه بايد مطالعه شود.

بلهور خلاصه مىتوان اين كونه بيان كرد كه سيستم هال و ون من مون

${ }^{64}$ Hand-coding

${ }^{65}$ Wintget and Kramer

${ }^{66}$ Clark, Trinder, Kramer, Roth, \& Day

${ }^{67}$ Calvin S Hall

${ }^{68}$ Cleveland Ohio

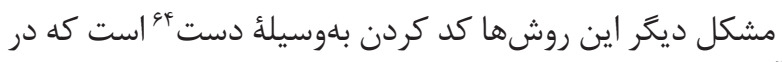

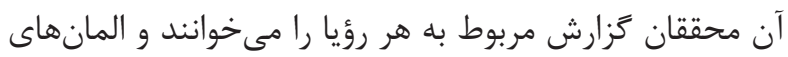

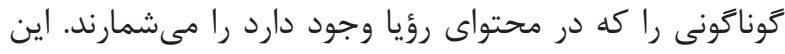

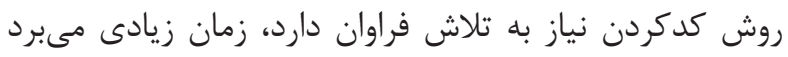

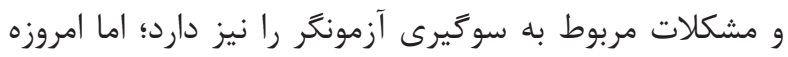

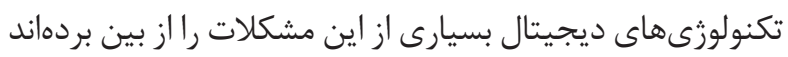

و ييشرفت بسيارى داشتهاند ( اله).

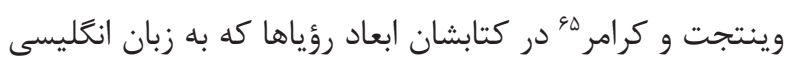

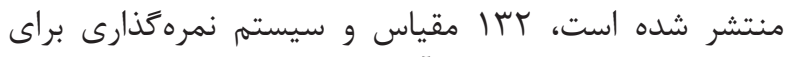

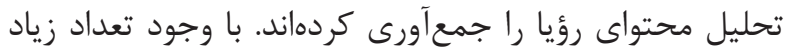

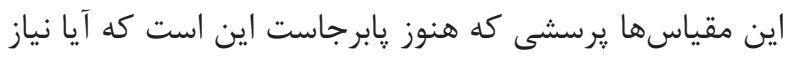

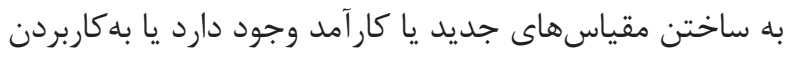

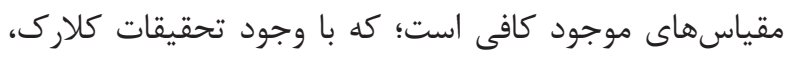

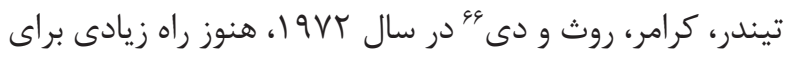
كسترش اين حوزه وجود دوارد دود

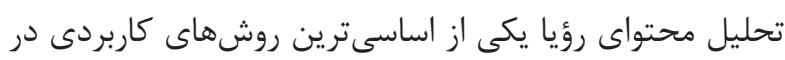

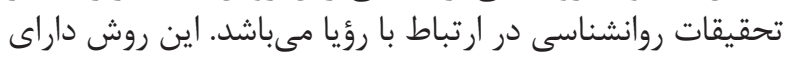

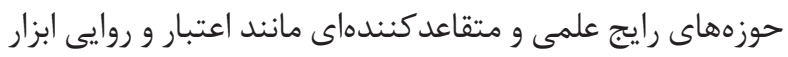

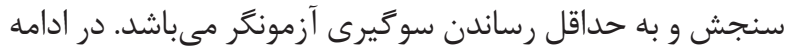

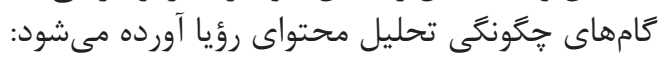
ا. . فرموله كردن يك فرضيه

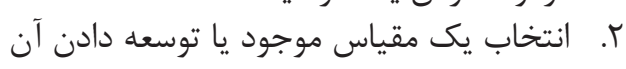

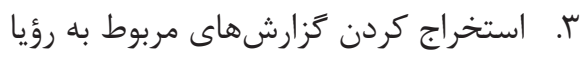

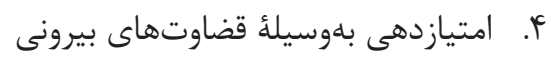

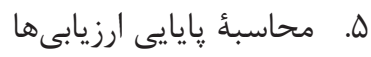

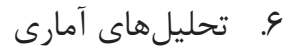

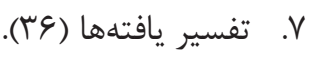

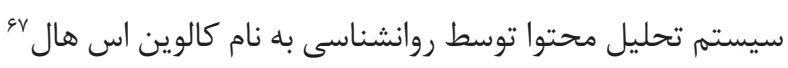

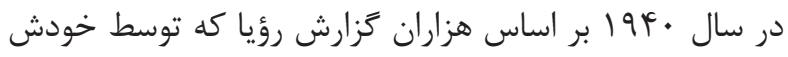

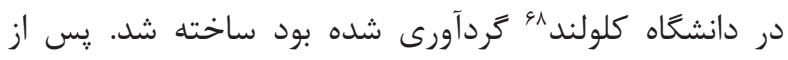

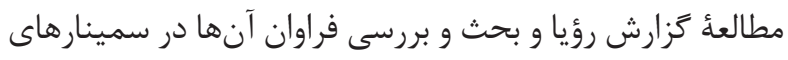

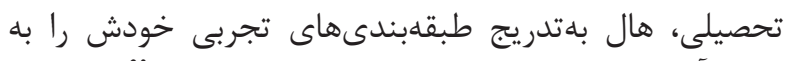

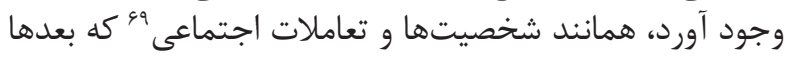

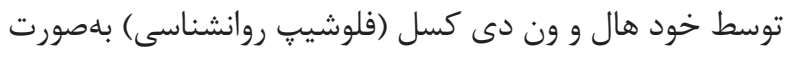
دقيق و رسمى توسعه يافت.

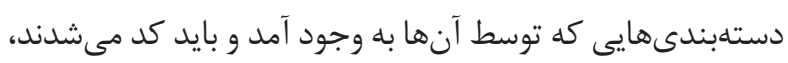

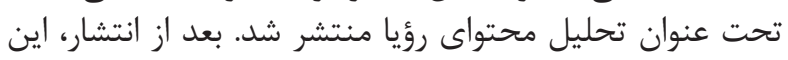

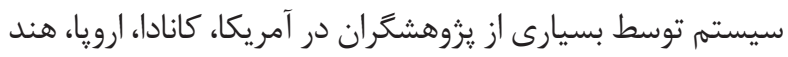

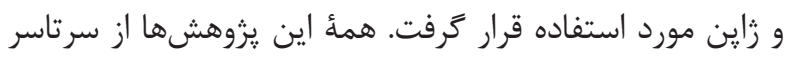

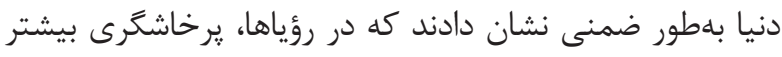

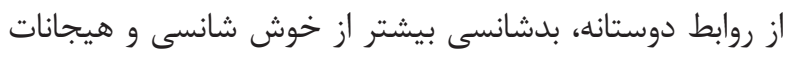

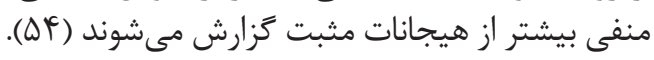

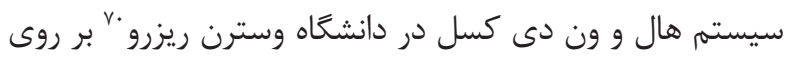

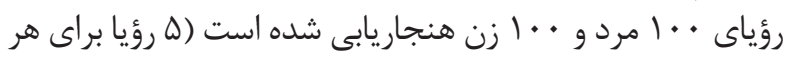

\footnotetext{
${ }^{69}$ Characters and social interactions

${ }^{70}$ Western Reserve University

${ }^{71}$ Objective and quantitative

${ }^{72}$ Symbolic interpretations
} 


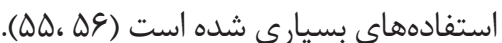
در قرون جديد نظريات مربوط به خواب و رؤيا با كارهاى فرويد، آدلر

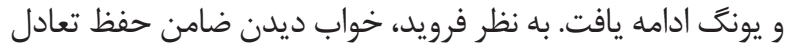

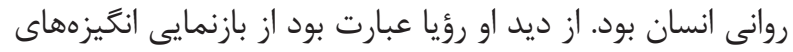

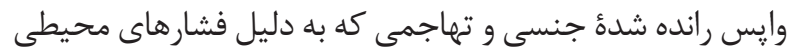

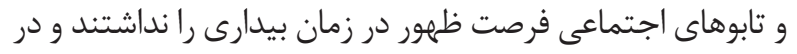

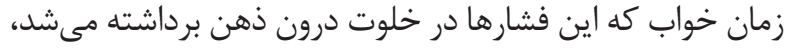
سرريز مىشدند و ظاهر مى حَشتند (هاب (1) ). يس از كارهاى فرويد، يزوهش در مورد رؤيا با كارهاى دامهوف،

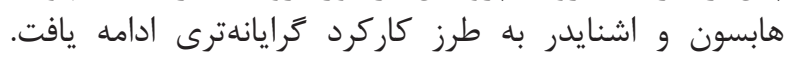

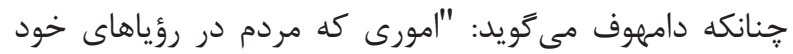

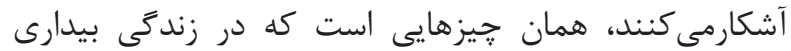

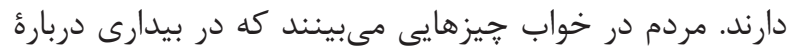
آنها فكر مى كنند يا كارى انجام مى دي دهند

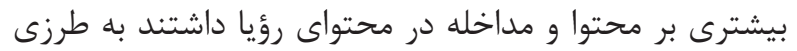

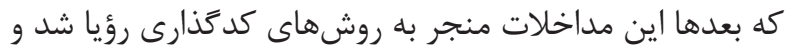

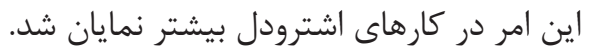

همجنين در عصر حاضر با تأكيد بر اختلالات خواب و و

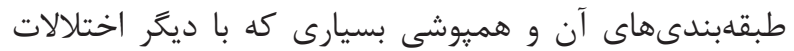

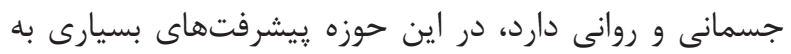
وجود آمده است.

لذا با توجه به كستردگى در اين حوزه و اهميتى كه در زند

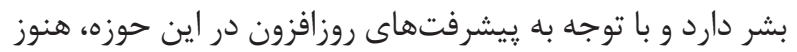

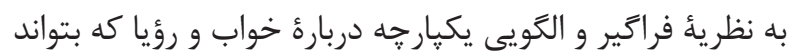

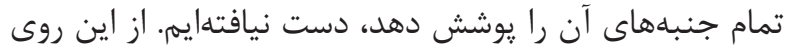

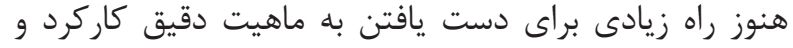
محتواى خواب و رؤيا مانده است.

1. Freud S. Revision of the theory of dreams. standard edition. London: The Hogarth Press. 1933; p. 7-30.

2. Eiser AS. Physiology and psychology of dreams. Semin Neurol; 2005; 25(1): 97-105.

3. Schredl M, Knoth IS. Nighttime in dreams. Percept Mot Skills. 2012.114(2): 457-60.

4. Dement W, Wolpert EA. The relation of eye movements, body motility, and external stimuli to dream content. J Exp Psychol Gen. 1958; 55(6): 543-53.

5. Suppiej A, Mento G, Zanardo V, Franzoi M, Battistella PA, Ermani M, et al. Auditory processing during sleep in preterm infants: an event related potential study. Early Hum Dev. 2010; 86(12): 807-12.

6. Oppenheim AL. The interpretation of dreams in the ancient near east. American Philosophical Society.
دى كسل، زَارش ثبت شده از رؤياها از نظر ميزان ديده شدن

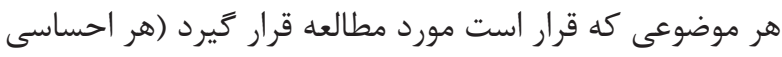

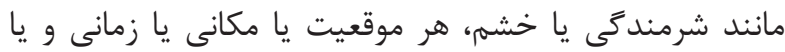

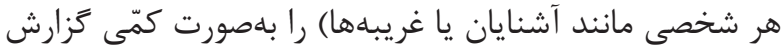

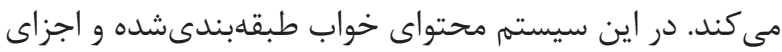

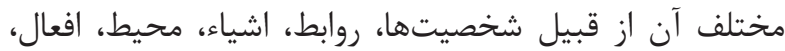

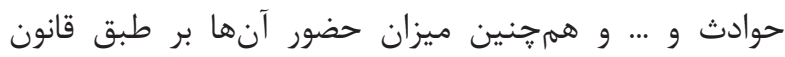

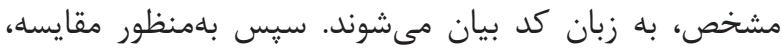

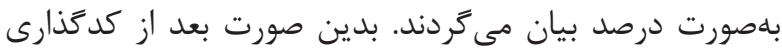

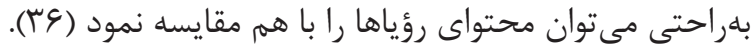

نتيجه كيرى

مقولهٔ رؤيا، با توجه به تصويرسازى منحصربهفردى كه در آن

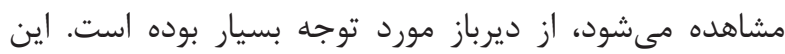

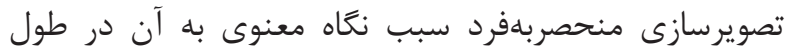

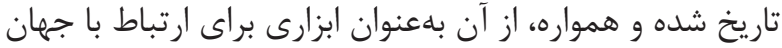

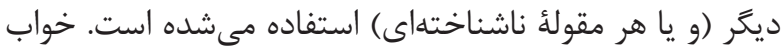

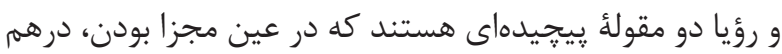
تنيدگى خاصى با يكديكر دارند.

نظريههاى مربوط به جِكَونَى و عملكرد رؤيا وخواب از آغاز تاريخ تا

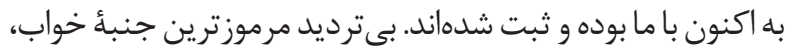

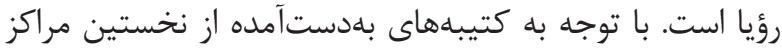

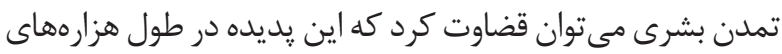

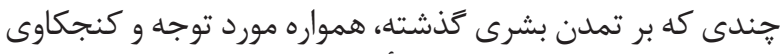

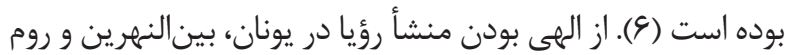

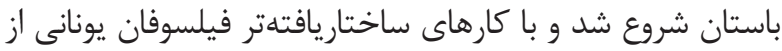

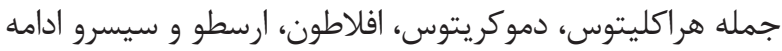

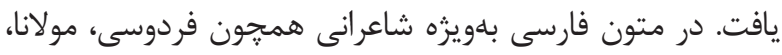

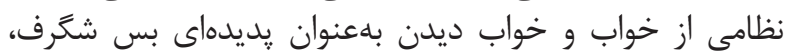

منابع

1956; p. 179-373.

7. Noegel S. Dreams and dream interpreters in mesopotamia and in the hebrew bible (old testament). Hampshire, UK: Palgrave-St. Martin's Press. 2001; p. 45-71.

8. Szpakowska K. Through the looking glass: dreams in ancient Egypt. dreams: a reader on the religious, cultural, and psychological dimensions of dreaming. New York: Palgrave. 2001; p. 29-44.

9. Dodds E. The Greeks and the irrational. Berkeley: University of California Press. 1951.

10. Jowett B. The dialogues of Plato. Oxford Clarendon Press. 1925.

11. Freud S. The interpretation of dreams. Hayes Barton Press. 1978. 
12. Barbera J. Sleep and dreaming in Greek and Roman philosophy. Sleep Med. 2008; 9(8): 906-10.

13. Wolman RN, Kozmová M. Last night I had the strangest dream: varieties of rational thought processes in dream reports. Conscious Cogn. 2007; 16(4): 838-49.

14. Calkins MW. Statistics of dreams. Am J Media Psychol. 1893; 5(3): 311-43.

15. Vakili Sh. Sleeping brain physiology and psychology of sleep and dreaming. $1^{\text {st }}$ ed. Tehran: Andishe Sara Pub. 2006; p. 30-5.

16. Ernest A. Dreams and dream interpretation. $1^{\text {st }}$ ed. Majid and Ferdows Publication. 1993; p. 40-1.

17. Fisher S. The scientific credibility of Freud's theories and therapy. Columbia University Press. 1985.

18. Evans C. Landscapes of the night: how and why we dream. 1st ed. New York City: The Viking Press. 1983.

19. Hobson JA. Dreaming as delirium: a mental status analysis of our nighty madness. Semin Neurol. 1997; 17(2): 121-8.

20. Cartwright RD. "Masochism" in dreaming and its relation to depression. Dreaming. 1992; 2(2): 79-84.

21. Cartwright RD. Dreams and adaptation to divorce. Cambridge, MA: Harvard University Press. 1996.

22. Domhoff GW, Hall CS. Finding meaning in dreams: a quantitative approach. Plenum, New York. 1996.

23. Hobson JA. The dreaming brain. Basic Books. 1989.

24. Botman HI, Crovitz HF. Dream reports and autobiographical memory. Imagin Cogn Pers. 1989; 9(3): 213-24.

25. Schneider A, Domhoff GW. Quantitative study of dreams. University of California, Santa Cruz. 2001.

26. Domhoff GW, Schneider A. Similarities and differences in dream content at the cross-cultural, gender, and individual levels. Conscious Cogn. 2008; 17(4): 1257-65.

27. Blagrove M. Problems with the cognitive psychological modeling of dreaming. J Mind Behav. 1196; 17: 99-134.

28. Gregory AM, O'Connor TG. Sleep problems in childhood: a longitudinal study of developmental change and association with behavioral problems. J Am Acad Child Adolesc Psychiatry. 2002; 41(8): 964-71.

29. Vogel GW. An alternative view of the neurobiology of dreaming. Am J Psychiatry. 1978; 135(12): 1531-5.

30. Hobson JA, McCarley RW. The brain as a dream state generator: An activation-synthesis hypothesis of the dream process. Am J Psychiatry. 1977; 134(12): 1335-48.

31. Buzsák G. Memory consolidation during sleep: a neurophysiological perspective. J Sleep Res. 1998; 7 Suppl 1: 17-23.

32. Hodo DW. Kaplan and sadock's comprehensive textbook of psychiatry. Am J Psychiatry. 2006; 163(8): 1458.

33. Schlarb AA, Reis D, SchröderA. Sleep characteristics, sleep problems, and associations to quality of life among psychotherapists. Sleep Disord. 2012; 2012: Article ID 806913: 1-7.

34. Charles M. The psychology of insomnia. $1^{\text {st }}$ ed. Yazd University Publication. 2002; p. 52-3.

35. Carskadon MA, Dement WC. Normal human sleep: an overview. W.B. Saunders, Philadelphia. 1989; p. 3-13.

36. Schredl M. Dream content analysis: basic principles. Int J Dream Res. 2010; 3(1): 65-73.

37. Lange T, Dimitrov S, Born J. Effects of sleep and circadian rhythm on the human immune system. Ann N Y Acad Sci. 2010; 1193: 48-59.

38. Adan A, Archer SN, Hidalgo MP, Di Milia L, Natale V, Randler C. Circadian typology: A comprehensive review. Chronobiol Int. 2012; 29(9): 1153-75.

39. Waterhouse J, Atkinson G, Edwards B, Reilly T. The role of a short post-lunch nap in improving cognitive, motor, and sprint performance in participants with partial sleep deprivation. J Sports Sci Med. 2007; 25(14): 1557-66.

40. Mölle M, Marshall L, Gais S, Born J. Grouping of spindle activity during slow oscillations in human nonrapid eye movement sleep. J Neurosci. 2002; 22(24): 10941-7.

41. Andersen ML, Alvarenga TF, Mazaro-Costa R, Hachul HC, Tufik S. The association of testosterone, sleep, and sexual function in men and women. Brain 
Res. 2011; 1416: 80-104.

42. Nicolas A, Gauthier A, Trouillet J, Davenne D. The influence of circadian rhythm during a sustained submaximal exercise and on recovery process. J Electromyogr Kinesiol. 2008; 18(2): 284-90.

43. Chtourou H, Zarrouk N, Chaouachi A, Dogui M, Behm DG, Chamari K, et al. Diurnal variation in Wingatetest performance and associated electromyographic parameters. Chronobiol Int. 2011; 28(8): 706-13.

44. Squarcini CF, Pires ML, Lopes C, Benedito-Silva AA, Esteves AM, Cornelissen-Guillaume G, et al. Freerunning circadian rhythms of muscle strength, reaction time, and body temperature in totally blind people. Eur J Appl Physiol. 2013;113(1): 157-65.

45. American Psychiatric Association. Diagnostic and statistical manual of mental disorders. $3^{\text {rd }}$ ed. American Psychiatric Association (APA); 1980.

46. Borkovec TD, Grayson JB, O'Brien GT, Weerts TC. Relaxation treatment of pseudoinsomnia and idiopathic insomnia: an electroencephalographic evaluation. J Appl Behav Anal. 1979; 12(1): 37-54.

47. Epstin LJ, Kristo D, Strollo PJ, Friedman N, Malhotra A, Patil SP, et al. Clinical guideline for the evaluation, management and long-term care of obstructive sleep apnea in adults. J Clin Sleep Med. 2009; 5(3): 263-76.

48. Ekbom K, Ulfberg J. Restless legs syndrome. J
Intern Med. 2009; 266(5): 419-31.

49. Chung WS, Chen YF, Lin CL, Chang SN, Hsu WH, Kao CH. Sleep disorders increase the risk of venous thromboembolism in individuals without sleep apnea: a nationwide population-based cohort study in Taiwan. Sleep Med. 2015; 16(1): 168-72.

50. Mazarakis T. A case of adult night terrors. TCMJ. 2014; 26(3): 138-40.

51. Bulkeley K. Digital dream analysis: a revised method. Conscious Cogn. 2014; 29: 159-70.

52. Yamanaka T, Morita Y, Matsumoto J. Analysis of the dream contents in japanese college students by rempawakening technique. Folia Psychiatr Neurol Jpn. 1982; 36(1): 33-52.

53. Fantini M, Corona A, Clerici S, Ferini-Strambi L. Aggressive dream content without daytime aggressiveness in REM sleep behavior disorder. Neurology. 2005; 65(7): 1010-5.

54. Castle HD. Dreams: Coding rules. 17 Feb. 2015. www.Dreamresearch.net.

55. Assad M. A comparative study sleep and dreaming and ideas Quran Maulana Rumi. comp Polit Stud. 2009; 11(3): 29-58.

56. Anbarani P. Sleep and dreaming in Shahnameh. The letter Parsi Journal. 2012; 31(1): 214-32. 